Article publié par le Laboratoire de Construction en Béton de l'EPFL

\begin{tabular}{|l|l|}
\hline Title: & Punching of flat slabs supported on rectangular columns \\
\hline Authors: & Sagaseta J., Tassinari L., Fernández Ruiz M., Muttoni A. \\
\hline Published in: & Engineering Structures \\
\hline DOI & $10.1016 /$ j.engstruct.2014.07.007 \\
\hline $\begin{array}{l}\text { Volume: } \\
\text { Pages: }\end{array}$ & $\begin{array}{l}77 \\
\text { pp. } 17-33\end{array}$ \\
\hline Year of publication: & 2014 \\
\hline Type of publication: & Peer reviewed journal article \\
\hline
\end{tabular}




\title{
Punching of flat slabs supported on rectangular columns
}

\author{
J. Sagaseta ${ }^{\mathrm{a}, *}$, L. Tassinari $^{\mathrm{b}}$, M. Fernández Ruiz ${ }^{\mathrm{c}}$, A. Muttoni $^{\mathrm{c}}$ \\ a University of Surrey, Guildford, United Kingdom \\ ${ }^{\mathrm{b}}$ University of Applied Sciences Western Switzerland HES-SO-HEIG-VD, Yverdon les Bains, Switzerland \\ ' École Polytechnique Fédérale de Lausanne (EPFL), Lausanne, Switzerland
}

\section{A R T I C L E I N F O}

Article history:

Received 18 September 2013

Revised 4 July 2014

Accepted 8 July 2014

\section{Keywords:}

Punching

Critical shear crack theory

Design models

Shear field

Experimental programme

Flat slabs

Rectangular columns

\begin{abstract}
A B S T R A C T
This paper investigates the structural behaviour of RC flat slabs supported on rectangular interior columns and the influence of the loading conditions (one or two-way bending) on their punching shear strength. The punching shear strength of slabs at rectangular columns can be lower than at equivalent square columns with a similar length of the control perimeter. This is due to a potential concentration of shear forces along the control perimeter. Some, but not all design formulas for punching design, consider this reduction on strength using empirical factors, which are written in terms of the column geometry only. However, in reality, the concentration of shear forces depends also on the deflected shape of the slab. It is shown in this paper that this can be consistently considered by means of the shear-resisting control perimeter. A sound approach is presented to estimate the shear-resisting control perimeter based on the shear fields of the slab accounting for the loading and boundary conditions. An alternative approach is presented based on the contact pressure in the support region which gives comparable predictions of the shear-resisting control perimeter. Both approaches give a physical explanation of the phenomenon. It is also shown that the model previously developed by the authors for non-axis-symmetrical punching of square columns based on the critical shear crack theory can also be applied to rectangular columns. Four punching shear tests are presented of slabs with one-way \& two-way bending to validate the theoretical models presented. Accurate strength and deformation capacity predictions were obtained for the tests investigated.
\end{abstract}

(c) 2014 Elsevier Ltd. All rights reserved.

\section{Introduction}

Reinforced concrete flat slabs supported on rectangular columns, with an elongated cross-section in one direction, are commonly used in practice, for example in underground parking garages and multi-storey buildings. Rectangular columns are typically used to reduce the effective span length (i.e. distance between inner faces of adjacent columns) and to provide lateral stiffness to the structure. Punching shear around such columns is generally the governing design criterion in flat slabs for the ultimate limit states. With respect to circular or square columns, there are two main concerns regarding punching shear around rectangular columns

(a) Actual (non-uniform) distribution of shear forces along the control perimeter around the column.

* Corresponding author. Address: Faculty of Engineering and Physical Sciences, Civil Engineering C5, Guildford, Surrey GU2 7XH, United Kingdom. Tel.: +44 (0) 1483686649.

E-mail address: j.sagaseta@surrey.ac.uk (J. Sagaseta). (b) Influence of the loading conditions and bending moments on the opening of the critical shear crack widths leading to punching failure.

These two concerns are also relevant in cases of punching shear in connections with moment transfer although in this paper only concentric loading will be investigated.

The distribution of normal stresses in large or elongated columns is non-uniform near the intersection with the slab. This was observed experimentally by several researchers such as Moe [1], Hawkins et al. [2], Vanderbilt [3] and Urban [4], amongst others. These tests showed that the strains measured in the concrete at the columns concentrated at the corners whereas the distribution of strains was uniform along circular columns with similar perimeters. Fig. $1 \mathrm{a}$ and $\mathrm{b}$ show the influence of the loading conditions and that this can result in a concentration of stresses at the column by considering two eccentric contact surfaces between the column and the slab.

The concentration of normal stresses at the column is influenced mainly by the column geometry and slab deformations in bending as shown schematically in Fig. 1a and b. However, most 


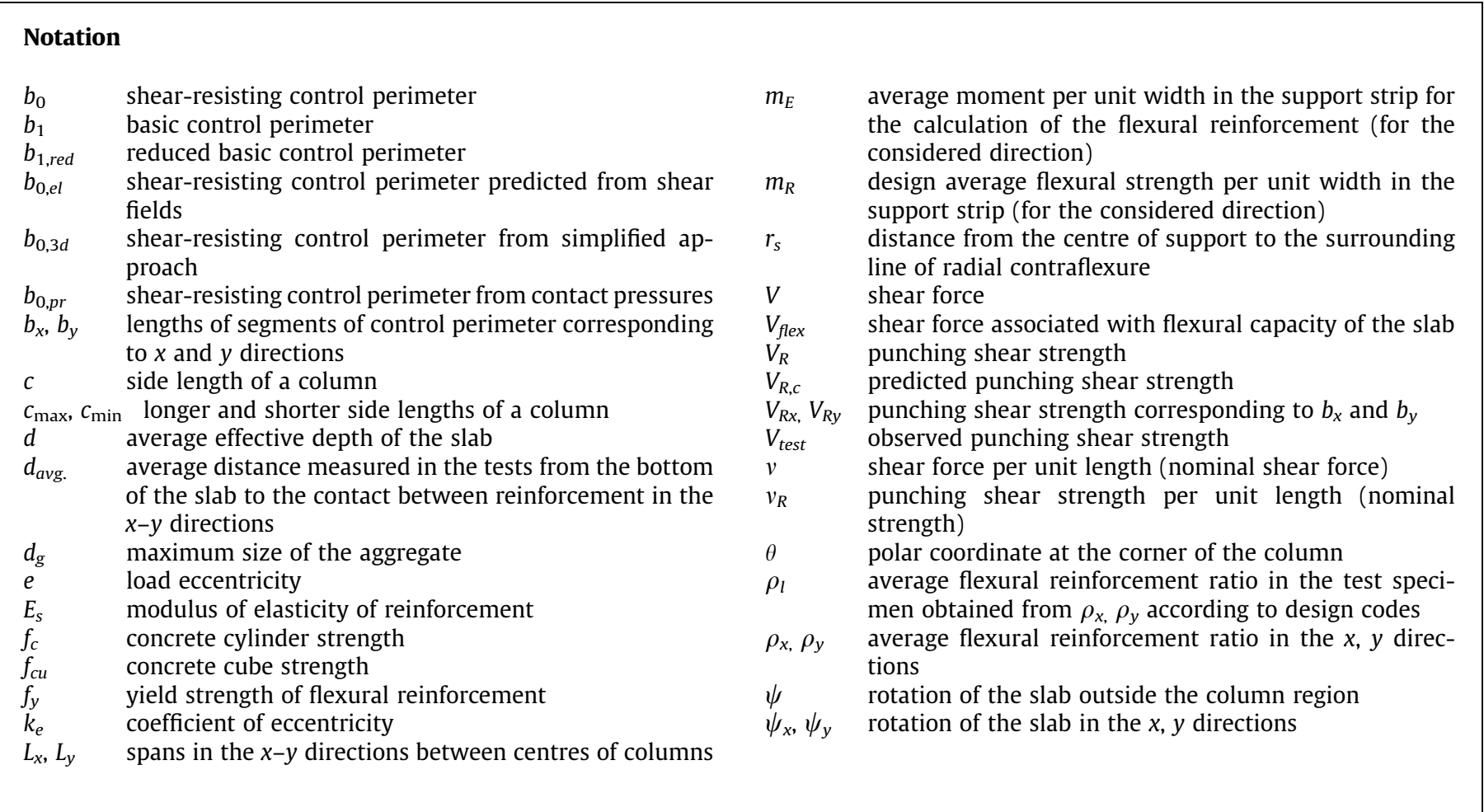

design approaches for punching only consider the column geometry in the calculations. The concentration of stresses is also influenced by the type of slab-column connection used (e.g. slab simply supported on the column or monolithically connected). It is noteworthy that concentration of shear forces can occur around interior rectangular columns even if loaded concentrically (i.e. balanced moments, $e=0$ ). The punching shear strength of slabs at rectangular columns can be overestimated if the concentration of shear forces along the control perimeter is neglected in the calculations.

Another aspect regarding punching shear around rectangular columns is that the development of one-way bending action is enhanced especially in columns with one side considerably longer than the other and $c_{\max }$ in the direction parallel to the predominant bending moment. This effect is also influenced by the clear span length between adjacent columns in both orthogonal directions.
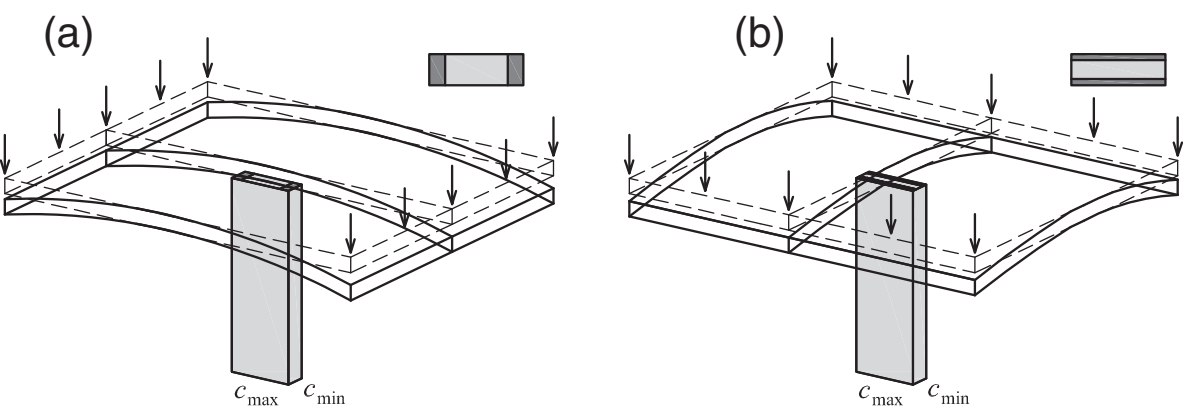

(c)

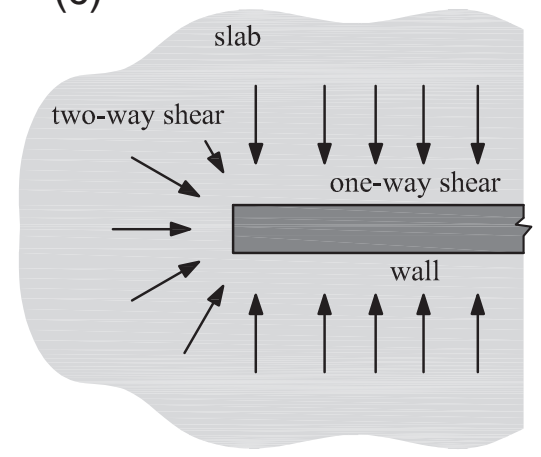

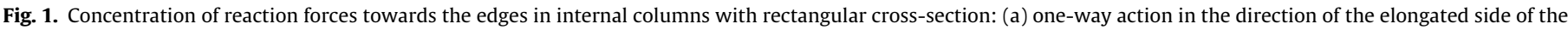
column $\left(c_{\max }\right)$; (b) one-way action in the direction perpendicular to $c_{\max }$ and $(\mathrm{c})$ one-way shear and two-way shear in a slab supported by a wall. 
(a) MC78 [7] and EC2 (1984) [8] $\lambda=0.5 d$

EC2 (1992) [9] $\lambda=1.5 d$

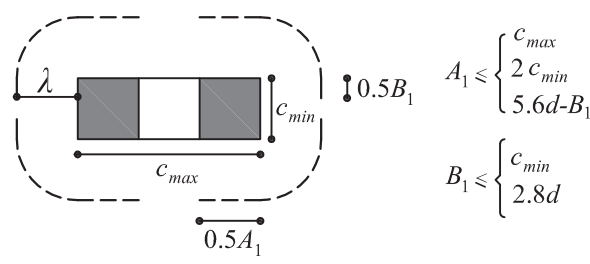

(b) $\mathrm{MC} 2010[17] \quad \lambda=0.5 d$ SIA $262[16] \quad \lambda=0.5 d$
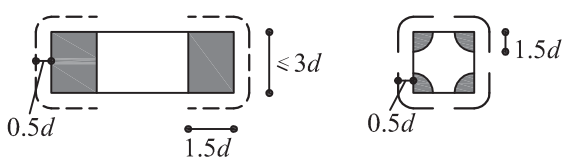

Fig. 2. Reduction of basic control perimeter for two-way shear according to different design methods: (a) Model Code MC78 [7], EC2 (draft versions 1984 [8] and 1992 [9]) (Note: in EC2 final version [12] $\lambda=2 d$ and the entire basic perimeter is considered); and (b) Swiss design code SIA 262 [16] and new Model Code MC2010 [17].

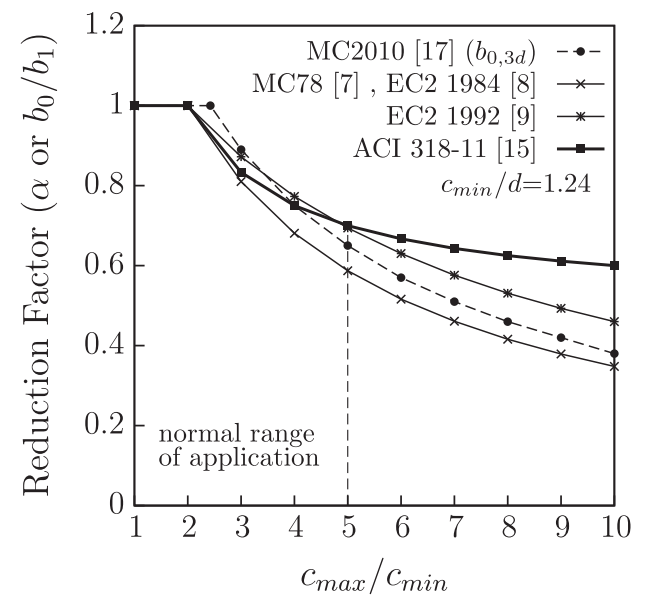

Fig. 3. Punching shear reduction factor in internal columns due to column geometry according to different design codes ( $\alpha$ for ACI 318-11 or $b_{0} / b_{1}$ for the remaining codes).

The contribution of one-way and two-way shear (Fig. 1c) is difficult to uncouple and current codes of practice often do not cover these design situations as recognized by Vaz Rodrigues et al. [5]. The shear-resisting control perimeter around rectangular columns can be quite long in such cases and the contribution from each segment of the control perimeter towards the punching shear strength is uncertain. This uncertainty is particularly significant in slabs where the deformations are clearly different in both orthogonal directions (non-axis-symmetrical punching). It is shown in this paper that in such cases, the punching strength can vary along the control perimeter leading to a similar redistribution of shear near failure to that of square columns [6].

This paper shows that the concentration of shear forces near the corners and the interaction between one-way and two-way action can be considered realistically using shear field analysis or a proposed method based on the contact pressure in the support region. Grounded on its results both approaches are shown to be selfconsistent and provide realistic predictions of the shear-resisting control perimeter required for calculating the punching strength. It is also shown that the model previously developed by the authors for non-axis-symmetrical punching around square (a)

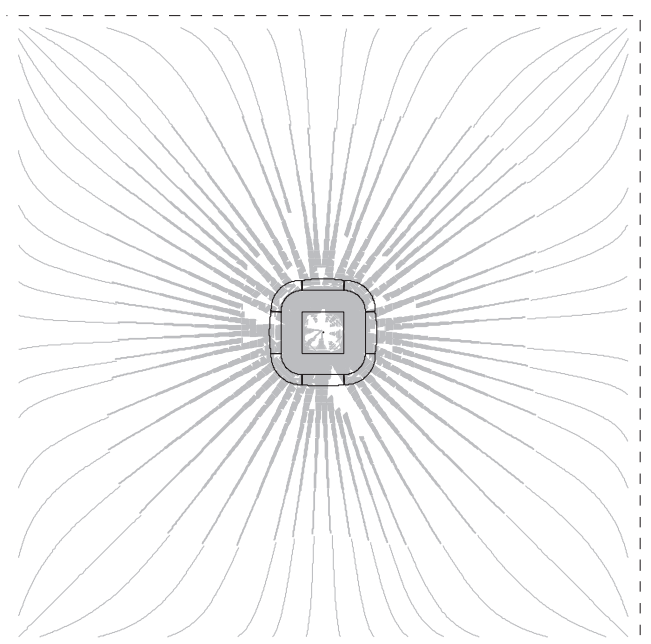

(b)

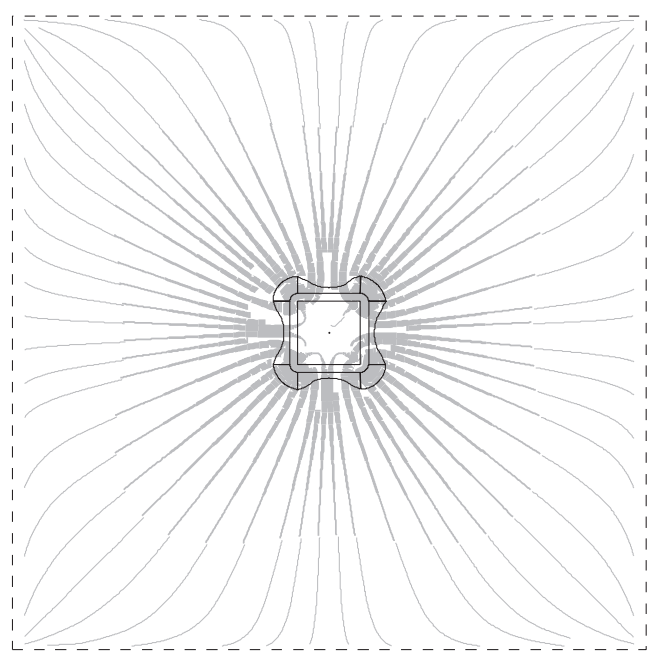

(c)

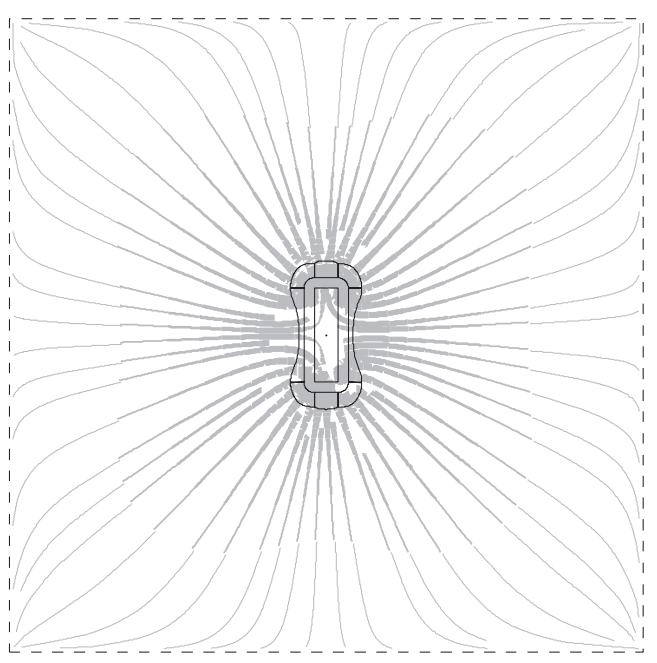

Fig. 4. Shear fields and distribution of nominal shear forces along control perimeter at $0.5 d$ from the column face for internal columns with (a) $c / d=1$, (b) $c / d=4$ and (c) $c_{\max } / c_{\min }=4$ and $c_{\min } / d=1.24$. Notes: The edges marked with dash lines correspond to planes of symmetry. Slabs under uniform distributed load with columns fixed to the slab.

columns [6] can be extended to rectangular columns. This paper also presents the experimental results from a series of four punching shear tests carried out at École Polytechnique Fédérale de Lausanne (EPFL) to validate the proposed approaches. 


\section{Background of existing design methods for punching for rectangular columns}

The historical development of design formulas for punching shear considered column rectangularity differently depending on the code used. Model Code 1978 [7] and first draft to Eurocode 2 in 1984 [8] provided specific rules for punching around rectangular columns as shown in Fig. 2a. The main difference between the two approaches was that in the latter method, the resistance of the straight segments neglected in the control perimeter was checked against one-way shear. In the Model Code 1978 approach, the shear forces corresponding to one-way and two-way shear were added to obtain the strength, with the limiting shear stresses at the corners taken as 1.6 times that for one-way shear. In the later draft version of Eurocode 2 in 1992 [9], the resistance of these segments was neglected and the control perimeter was reduced as shown in Fig. $2 \mathrm{a}$ although the value of $\lambda$ was $1.5 d$. The considerations on column size and shape adopted in [9] were found to give rather conservative predictions [10].

The design recommendations for elongated columns were finally removed in Model Code 1990 [11] and in the final version of Eurocode 2 in 2004 [12] which defined the control perimeter at a distance of $\lambda=2 d$ from the column face. Only in MC90 [11] a comment was included for complex situations such as elongated columns in which further structural analyses were recommended in such cases, although it was not specified the type of analysis required. The removal of special clauses for rectangular columns in $[11,12]$ was based on the assumption that the shear stress was

(a)

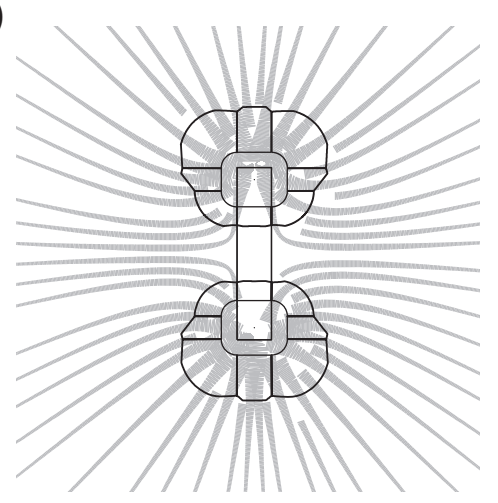

(c)

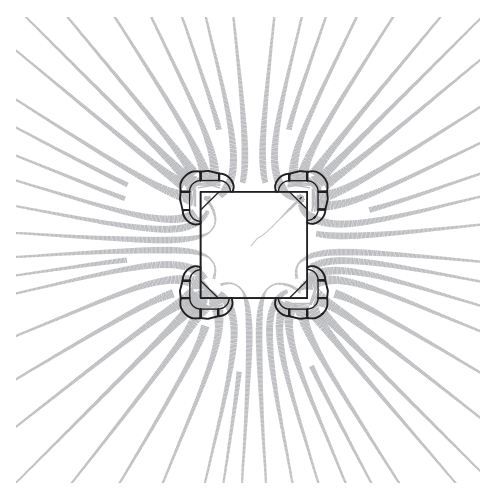

uniform along the new control perimeter adopted. It also allowed using the same formula for calculation of the shear strength in punching as for one-way shear. BS8110 [13] code with $\lambda=1.5 d$ shared the same philosophy as Eurocode 2 [12], although work by $[10,14]$ raised some concerns on this assumption for slabs loaded in one-way action. Researchers $[10,14]$ proposed empirical factors to be applied in BS8110 formulas to consider the reduction in punching strength in different one-way bending situations depending on the orientation of the column.

Design code ACI 318-11 [15] define the control perimeter at $\lambda=0.5 d$ and introduce considerations for rectangular columns based on limiting the maximum allowable shear stress using parameter $\alpha$ (refer to Appendix A of this paper). This parameter was introduced after the work from $[2,3,18]$ and takes into account the effect of column rectangularity $\left(c_{\max } / c_{\min }\right)$ and the relative size $\left(d / b_{1}\right)$ where $b_{1}$ is the basic control perimeter. Codes MC78 [7], SIA 262 [16] or the new Model Code 2010 [17], which also define the control perimeter at $\lambda=0.5 d$, use an alternative approach to consider column rectangularity. These approaches apply the concept of reduced effective control perimeter in their formulas, which is also referred to as "shear-resisting control perimeter" $\left(b_{0}\right)$. The basic control perimeter $\left(b_{1}\right)$ is reduced $\left(b_{1, \text { red }}\right)$ to take into account of the potential concentration of shear due to the column shape. Fig. $2 \mathrm{~b}$ shows the reduction of the basic perimeter in rectangular columns and square columns with $c / d>3$ adopted by MC2010 [17] and SIA 262 [16] codes. The shear-resisting control perimeter obtained using this approach is referred to in this paper as $b_{0,3 d}$. This approach is in agreement with experimental observation by (b)
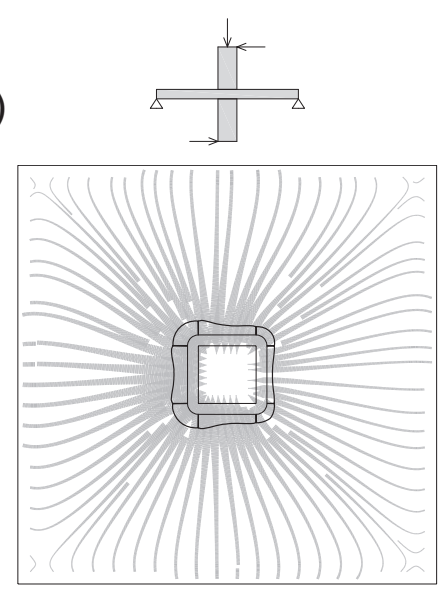

(d)

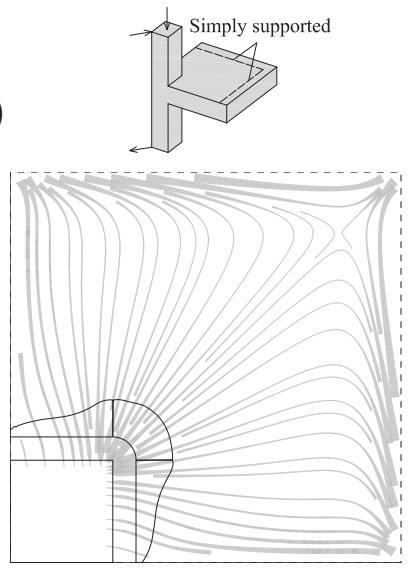

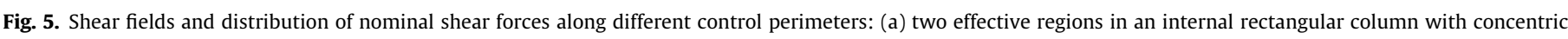

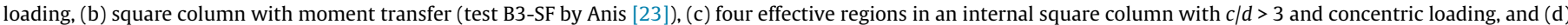

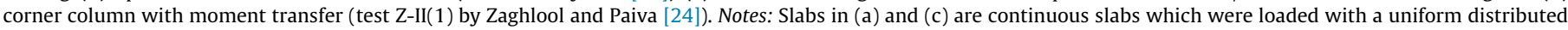
load whereas in (b) and (d), the load was introduced in the model at the columns as in the tests. The columns were fixed to the slab in the four cases. 
ACI-ASCE Committee 426 on Shear and Diagonal Tension [19] that the increase in the shear stresses at failure for $c / d$ ratios greater than 3 is negligible. Fig. 3 shows that for size columns in which $c$ is similar to $d$ (e.g. $c_{\min } / d=1.24$ ) which is typical for elongated columns, the reduction in strength proposed by ACI 318-11 [15] using parameter $\alpha$ is comparable to the $b_{0,3 d} / b_{1}$ ratio proposed in MC2010 [17] and $b_{0} / b_{1}$ adopted by MC78 [7] and EC2 in 1992 [9].

In practice, the length of the reduced basic perimeter is still to be multiplied by coefficient $k_{e}\left(b_{0}=k_{e} b_{1, \text { red }}\right)$ to take into account for unavoidable stress concentrations which can be due to potential eccentricities in the load resulting from loads near the columns or resulting from the clamping effect between the column or wall and the slab. Codes $[16,17]$ recommend a value of $k_{e}$ equal to 0.9 for inner columns and 0.75 for corners for walls (assuming that adjacent spans do not differ in length by more than $25 \%$ and that lateral stability does not depend on frame action of slabs and columns). The tests and case studies discussed in this paper correspond to slabs in which the loading and boundary conditions are well known and therefore the eccentricities can be safely assumed to be zero $\left(k_{e}=1\right)$. A similar approach was followed by Muttoni [20] for punching around square columns.

\section{Consistent estimation of the shear-resisting control perimeter $\left(b_{0}\right)$}

\subsection{Calculation based on shear field analysis}

Fig. 1 shows that the potential concentration of normal stresses at the column depends mainly on the bending deformations of the slab in combination with the column geometry. For simplicity reasons, the design codes described previously consider the column geometry only but not the actual loading conditions of the slab. Researchers [5,6,21] have demonstrated that shear field analysis can be a very practical tool to understand the load-carrying mechanisms of RC flat slabs. This approach, which considers slab deformations, allows estimating the effective perimeter $\left(b_{0}\right)$ for general cases of geometry and loading.

The shear fields can be obtained from a simple FE elastic analysis with linear-elastic behaviour for the concrete and a realistic stiffness in torsion due to cracking (the shear modulus was taken as $1 / 8$ of its elastic value as normally adopted in practice). The results from the shear field analyses are generally presented as flow lines along the principal directions with a line thickness proportionate to the magnitude of the shear force per unit length $[5,6]$. An example of this is shown in Fig. 4. The shear force vectors perpendicular to the control perimeter provide useful information on the distribution of shear and can be calculated numerically from post-processing of the shear forces from the FE elastic analysis. The length of the shear-resisting perimeter can be calculated using Eq. (1) proposed by Vaz Rodrigues et al. [5] and also considered in MC2010 [17].

$b_{0, e l}=\frac{V}{v_{\max }}$

where $b_{0, e l}$ is the length of the shear-resisting control perimeter obtained from the elastic shear field, $V$ is the total acting shear force and $v_{\max }$ is the maximum value of the unitary or nominal shear force (i.e. shear force per unit length along the perimeter). Fig. 4 shows the shear fields and distribution of nominal shear forces around a control perimeter at $\lambda=0.5 d$ from an internal square column with (a) $c / d=1$, (b) $c / d=4$ and (c) rectangular column with $c_{\max } / c_{\min }=4$ and $c_{\min } / d=1.24$. The size of the columns and slab depth were selected so that the length of the basic perimeter was equal in the three cases. Fig. 4 shows that the size and shape of the column has a significant influence on the distribution of nominal shear forces and the estimated value of $b_{0, e l}$. The shear field analyses show that shear forces concentrate around the shorter side of the rectangular column (Fig. 4c). This is in agreement with experimental data from Teng et al. [22] which showed high flexural stress gradients in this region. (a)

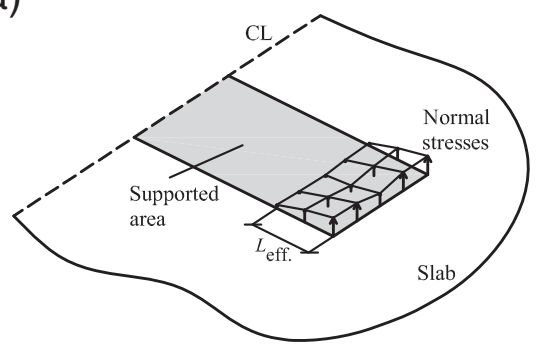

(c)

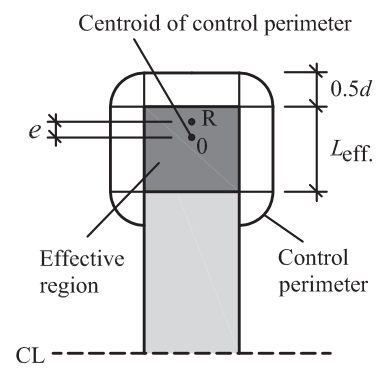

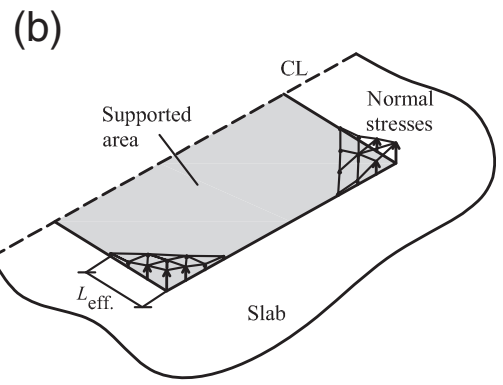

(d)

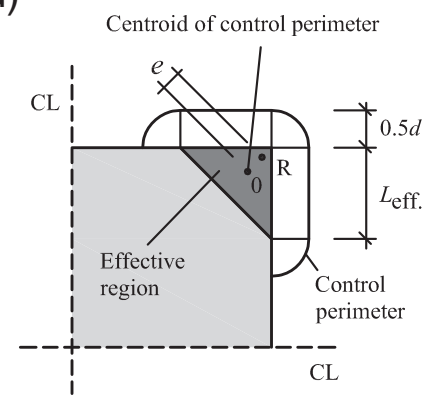

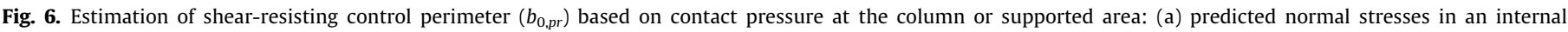

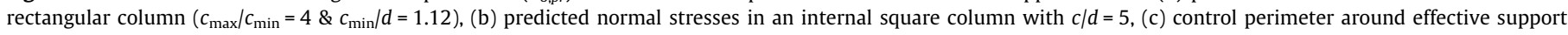

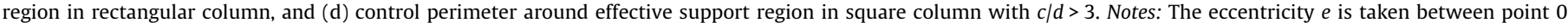

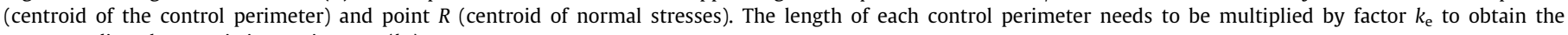
corresponding shear-resisting perimeters $\left(b_{0}\right)$. 
A relatively uniform distribution of the nominal shear forces as shown in Fig. 4 a results into a ratio $b_{0} / b_{1}$ close to 1 whereas in columns shown in Fig. $4 \mathrm{~b}$ and $\mathrm{c}$ the $b_{0} / b_{1}$ ratio obtained were 0.62 and 0.68 respectively. The same analysis was carried out using a control perimeter at $\lambda=2 d$ as suggested in EC2 [11], the $b_{0} / b_{1}$ ratio obtained in this case was close to 1 for the three columns shown in Fig. 4. This supports the assumption in EC2 of constant shear forces along the control perimeter for internal columns and slabs with two-way bending which can result in reasonable strength predictions. The main drawback of the EC2 control perimeter is the lack of physical meaning, in particular the previous example shows that the distance $\lambda=2 d$ is not suitable to capture the potential concentration of shear forces at the shear-critical region.

\subsection{Calculation based on contact pressure in the column}

A closer examination of the shear fields at the corners of rectangular columns shows that the slab is effectively supported at the two ends of the column (Fig. 5a). These areas, where the column is in compression, are designated in the following as "effective support regions". Oliveira et al. [14] also reported this phenomenon in their tests which is the basis behind the reduction of the basic perimeter for rectangular columns shown in Fig. 2b. It is noteworthy that the distribution of nominal shear forces along the perimeter surrounding each effective support region is non-uniform as shown in Fig. 5a (shear is highest at the shorter side of the column). This distribution of shear resembles to some extent to that observed in columns with a moment transfer in which larger shear forces develop on one side to balance the moment at the column (Fig. 5b). In square columns with $c / d>3$, the slab is essentially supported on four effective support regions, one at each corner as shown in Fig. 5c. Fig. 5d shows that the distribution of the nominal shear forces around the effective support region in square columns with $c / d>3$ is similar to that observed in corner columns with moderate eccentricity in the applied load.

The local transfer of shear can alternatively be understood by looking at the pressure that develops at the supported area. Fig. 6a and b show the normal compressive stresses at internal supports, obtained from FE analysis of slabs supported on elongated columns and square columns with $c / d>3$. Contact elements allowing for compression only, were used to model the column-slab interface in simply supported cases. The normal stresses obtained provided basic information about size ( $L_{\text {eff. }}$ ) and local contact pressure at each effective support region as shown in Fig. $6 a$ and b. Fig. $6 \mathrm{c}$ and $\mathrm{d}$ show the geometry of the perimeter corresponding to each effective support region. The total length of the shear-resisting control perimeter can be calculated by adding up the length of the control perimeters corresponding to each effective support region. The shear-resisting control perimeter obtained using this approach is denoted as $b_{0, p r}$. The control perimeter corresponding to each effective support region needs to be reduced by an eccentricity factor $k_{e}$ to consider the non-uniformity of the shear forces due to the localized moment transfer. Parameter $k_{e}$ can be obtained using Eq. (2) in MC2010 [17], which was proposed by the authors for corner, edge and internal columns with moment transfer:

$k_{e}=\frac{1}{1+e / b_{u}}$

where $b_{u}$ is the diameter of the circle with the same surface as the region inside the basic control perimeter and $e$ is the load eccentricity with respect to the centroid of the basic control perimeter. In a general case, $e$ is the eccentricity of the overall load reaction and thus $k_{e}=1$ in concentrically loaded columns. In this study, each effective support region is treated individually and so the eccentricity of the reaction is measured with respect to the centroid of the control perimeter around the effective support region (Fig. 6c and d). (a)

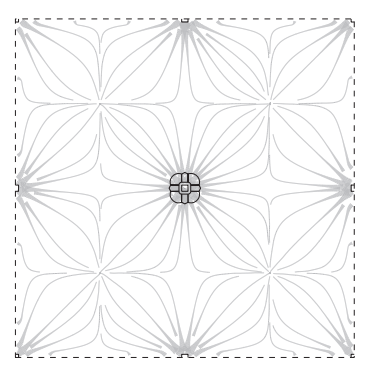

(d)

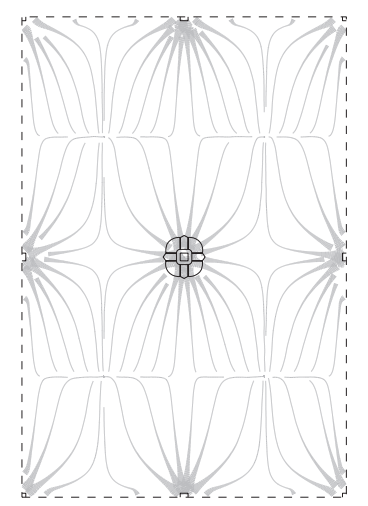

(b)

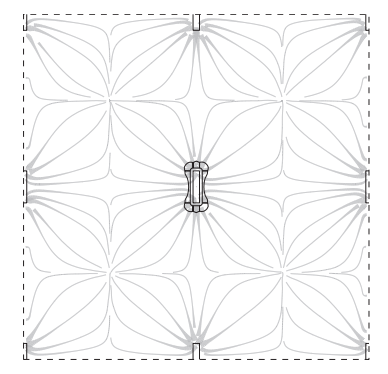

(e)

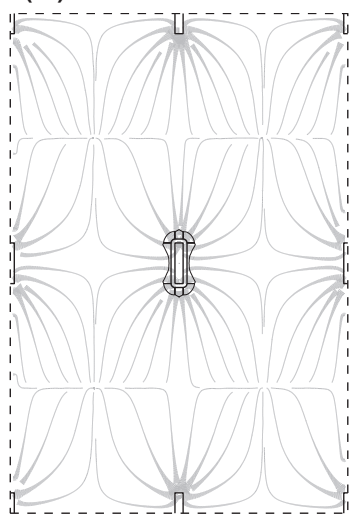

(c)

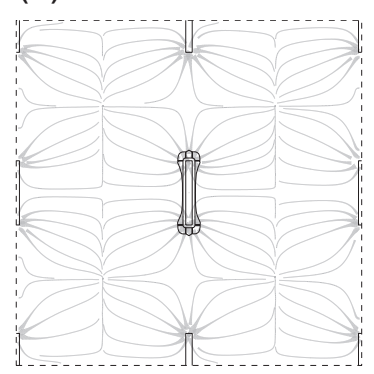

(f)

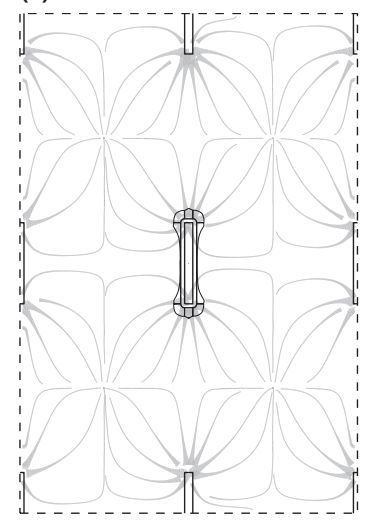

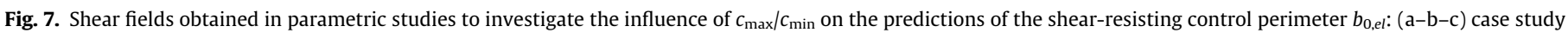

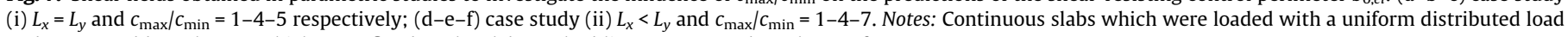
and supported by columns which were fixed to the slab. Dashed lines correspond to planes of symmetry. 
3.3. Comparison between shear-resisting control perimeters from shear field analysis, contact pressure and simplified formulas

The shear-resisting control perimeter was calculated for several interior columns with different sizes and column grid layouts, using the proposed method based on contact pressure $\left(b_{0, p r}\right)$, shear field analysis $\left(b_{0, e l}\right)$ and the simplified approach $\left(b_{0,3 d}\right)$ shown in Fig. $2 \mathrm{~b}$. The main objective of this analysis was to investigate the influence of the slab deformations on the predictions of the shear-resisting control perimeter for different design configurations. Three case studies were investigated: (i) flat slab with square bays $\left(L_{x}=L_{y}=7 \mathrm{~m}\right)$, (ii) flat slab with rectangular bays $\left(L_{x}=5 \mathrm{~m} \&\right.$ $L_{y}=8 \mathrm{~m}$ ), (iii) flat slabs with square bays $\left(L_{x}=L_{y}=10 \mathrm{~m}\right)$ and columns with large values of $c_{\min } / d$ between 2.5 and 5 . For each case
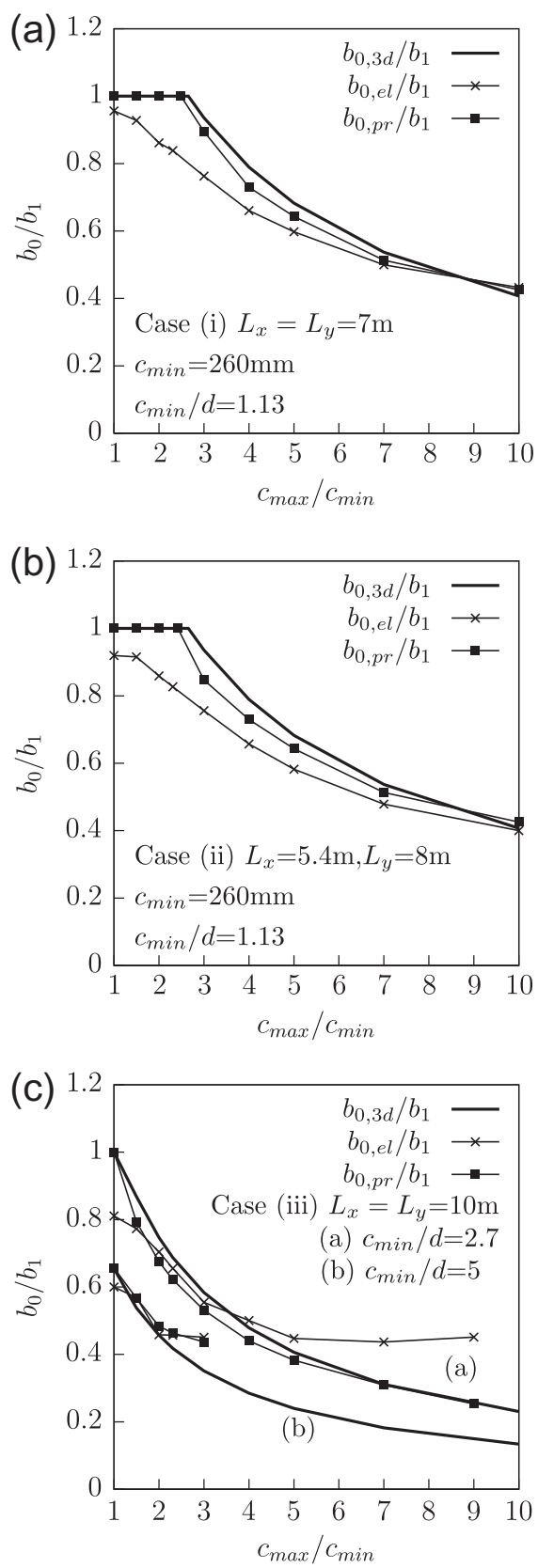

Fig. 8. Comparison of predicted shear-resisting control perimeter using proposed approach $\left(b_{0, p r}\right)$, shear stress fields $\left(b_{0, e l}\right)$ and simplified method $\left(b_{0,3 d}\right)$ in (a) case study (i), (b) case study (ii) and (c) case study (iii). study, a parametric analysis was carried out using different values of the $c_{\max } / c_{\min }$ ratio; different values of $c_{\max }$ were adopted from $260 \mathrm{~mm}$ to $2600 \mathrm{~mm}$ whilst keeping constant $c_{\min }=260 \mathrm{~mm}$, $d=230 \mathrm{~mm}$ and the spans between the centre of the columns $\left(L_{x}\right.$, $L_{y}$ ). The parametric analysis consisted of elastic FE analysis using shell elements to model the continuous slabs with rigid supports which consider the size of the column. A uniformly distributed load was applied in the models with restraints in the slab rotations at planes of symmetry. Fig. 7 shows some of the shear fields in case studies (i) and (ii).

Fig. 8 shows that the predictions of $b_{0}$ from the proposed method and the shear field analysis are consistent with each other for the cases investigated. Moreover, the results from the simplified approach $\left(b_{0,3 d}\right)$ are comparable to those from the contact pressure method for the three case studies investigated and $c_{\max } / c_{\min }$ up to around 5. In cases where the clear span length is sufficiently long and the slab has a two-way action, all the approaches predict a similar decrease of the $b_{0} / b_{1}$ ratio with increasing $c_{\max } / c_{\min }$ (Fig. 8). This reflects that the shear tends to concentrate around the short side of the column with increasing $c_{\max } / c_{\min }$ as shown in Fig. $7 \mathrm{c}$ and $\mathrm{f}$. However, for very elongated columns with a very small clear span between columns (i.e. large $c / L$ ratios), the proposed method and the shear field analysis predicts that the $b_{0} / b_{1}$ ratio increases with increasing $c_{\max } / c_{\min }$. This is shown in Fig. $8 \mathrm{c}$ for example for $c_{\min } / d=5$ and $c_{\max } / c_{\min }>2$ and appears to be related to the progressive development of the one-way action deformation (Fig. 1b). Simmonds [25] carried out a series of tests on slabs supported on rectangular columns followed by an elastic analysis using finite differences. From his numerical results he established that flat slab behave as a one-way slab when the ratio $c_{x} / L_{x}$ or $c_{y} / L_{y}$ exceeds 0.4 . This limit value agrees reasonably well with the results obtained in this work. In Fig. $8 c$ the $b_{0} / b_{1}$ ratio begins to increase for $c / L$ ratios around 0.35 .

The results shown in Fig. 8 suggest that the orientation of the column has a significant effect on the shear-resisting control perimeter. For instance, if the columns in case study (ii) with $L_{x}<-$ $L_{y}$ were orientated with $c_{\max }$ in the direction of $L_{x}$, the formation of the one-way bending mechanism will occur at lower values of $c_{\max } / c_{\min }$ compared to the case shown in Fig. $7 \mathrm{f}$ where the column is orientated with $c_{\max }$ in the direction of $L_{y}$. This is due to the reduced clear span in the $x$ direction. The combined effect of column rectangularity and span layout on the shear-resisting control perimeter can only be considered using the $b_{0, e l}$ and $b_{0, p r}$ approaches. A series of experimental tests were carried out in this work to investigate the influence of the orientation of the column with respect the main bending deformations. The distribution of the reaction forces was monitored during the tests as well as the slab deformations.

\section{Experimental programme}

\subsection{Test specimens}

Four slabs were tested at École Polytechnique Féderale de Lausanne (EPFL) without transverse reinforcement and supported on an internal rectangular steel plate with sides equal to $0.26 \mathrm{~m}$ and $0.78 \mathrm{~m}$ (Fig. 9a). The size of the specimens was $3 \mathrm{~m}$ by $3 \mathrm{~m}$ with a total thickness of $0.25 \mathrm{~m}$. The reinforcement ratio was the same for all the specimens $\left(\rho_{l}=0.75 \%\right)$ using $16 \mathrm{~mm}$ diameter bars equally spaced at $125 \mathrm{~mm}$ in both orthogonal directions. The nominal effective depth $(d)$ was $214 \mathrm{~mm}$, although the measured values in the specimens ranged from $214 \mathrm{~mm}$ to $202 \mathrm{~mm}$ as shown in Table 1. Reinforcement was provided on the compression face (0.42\%) using $12 \mathrm{~mm}$ bars equally spaced at $125 \mathrm{~mm}$. The specimens were designed using a similar reinforcement layout and 
(a)

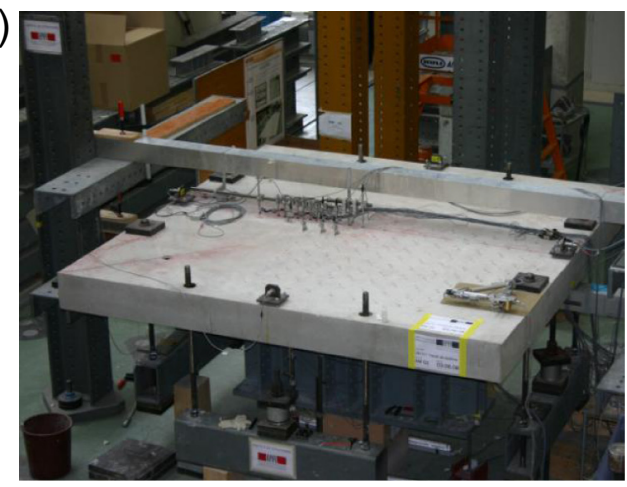

(b)

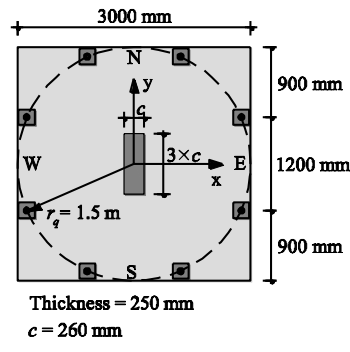

(d)

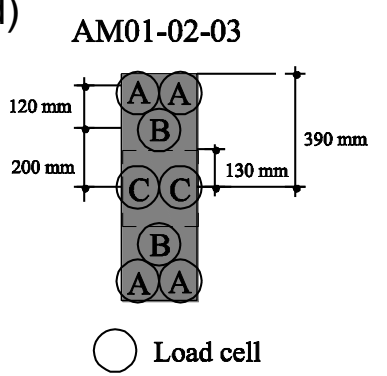

(c)

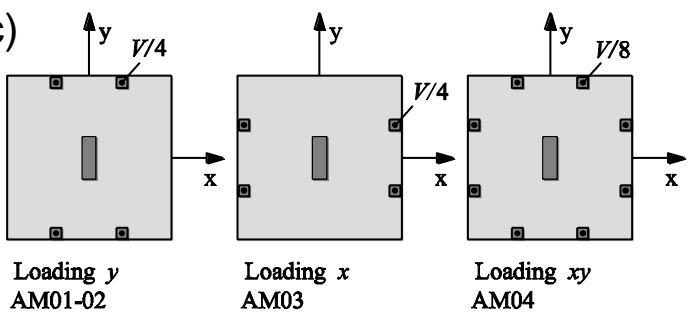

(e)

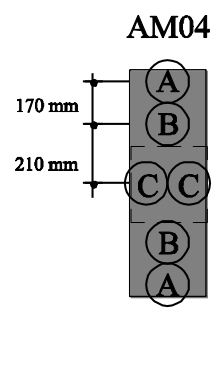

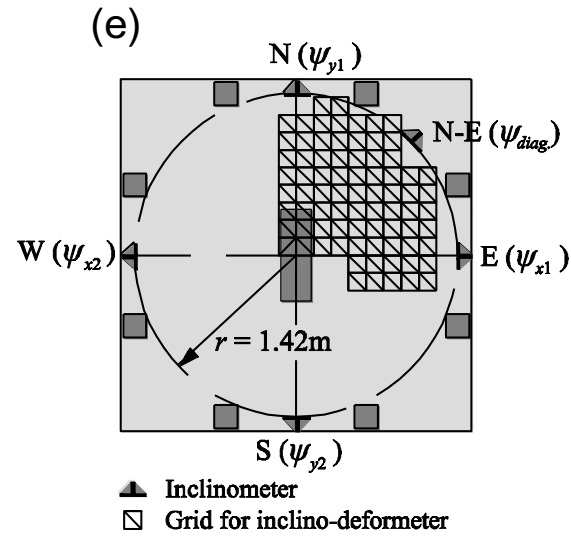

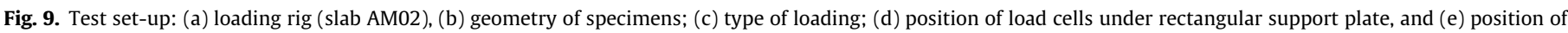
inclinometers for measuring slab rotations.

Table 1

Summary of test specimens and experimental results.

\begin{tabular}{llllc}
\hline Test & Loading & $d_{\text {avg. }}(\mathrm{mm})$ & $f_{c}(\mathrm{MPa})$ & $V_{\text {test }}(\mathrm{kN})$ \\
\hline AM01 & 1-way & 214 & 44.0 & 950 \\
AM02 & 1-way & 208 & 39.7 & 919 \\
AM03 & 1-way & 203 & 42.2 & 883 \\
AM04 & 2-way & 202 & 44.6 & 1067 \\
\hline
\end{tabular}

Notes: Reinforcement bars in the $y$ direction correspond to the inner layer.

geometry as previous tests carried out at EPFL with square columns and $c=0.26 \mathrm{~m}[6,26]$.

The only parameter varied in the four tests presented in this paper was the type of loading, which is summarized in Fig. 9b and $c$. In all specimens the resultants of the applied forces were at the centre of the slabs. Specimens AM01 and AM02 were identical and were loaded with one-way spanning along the direction of the elongated side of the column $c_{\max }$ with two point loads applied on the two opposite sides of the slab. AM03 was loaded similarly with one-way spanning along the direction perpendicular to $c_{\text {max }}$ whereas AM04 was loaded with two-way spanning at eight load points, two at each side of the specimen, as shown in Fig. 9c.
Table 2

Concrete mixture proportions.

\begin{tabular}{ll}
\hline Material & Series AM $\left(\mathrm{kg} / \mathrm{m}^{3}\right)$ \\
\hline Cement (NORMO4) & 325 \\
Sand $(0-4 \mathrm{~mm})$ & 820 \\
Gravel $(4-8 \mathrm{~mm})$ & 432 \\
Gravel $(8-16 \mathrm{~mm})$ & 621 \\
Water $(\mathrm{W} / \mathrm{C})$ & $159(0.49)$ \\
\hline
\end{tabular}

The load was introduced using $200 \mathrm{~mm}$ by $200 \mathrm{~mm}$ steel plates and $36 \mathrm{~mm}$ diameter Dywidag rods which were pulled with two and four hydraulic jacks placed underneath the reaction floor.

\subsection{Material properties}

The measured concrete cylinder strength at time of testing ranged from 39.7 MPa to $44.6 \mathrm{MPa}$ as shown in Table 1. Normal siliceous gravel was used for the concrete with a maximum aggregate size $\left(d_{g}\right)$ of $16 \mathrm{~mm}$. The mix proportions of the concrete are given in Table 2. Hot-rolled steel bars were used with a well defined yield plateau and a strain hardening branch. The yield 
(a)

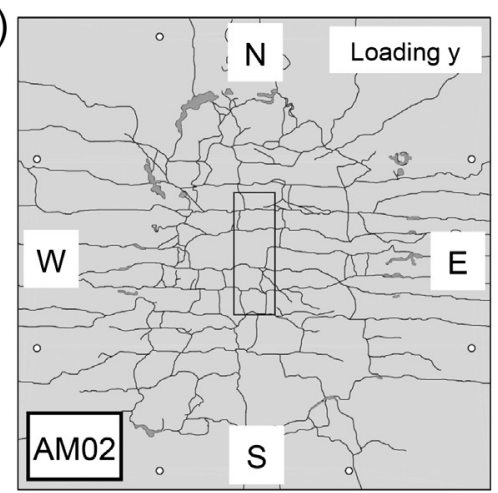

(c)

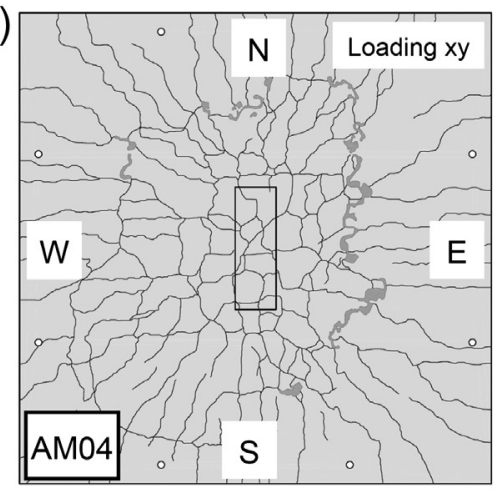

(b)

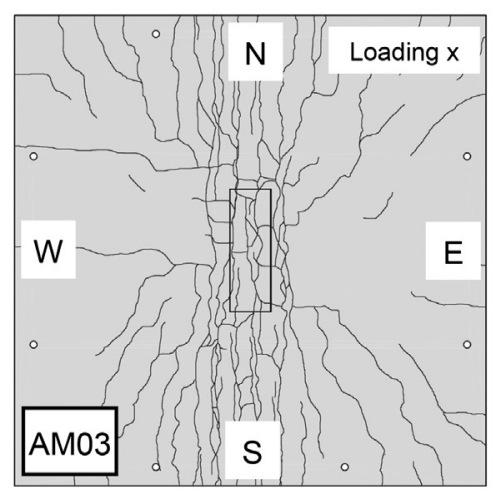

(d)
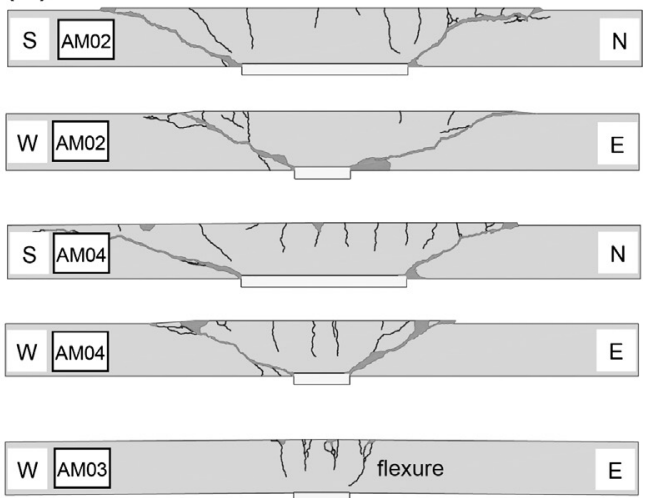

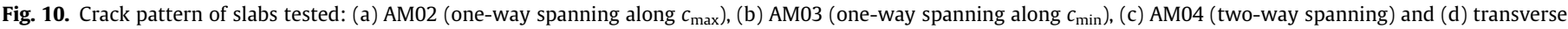
sections along $x-y$ axis of specimens AM02, AM03 and AM04.

strength of the reinforcement measured from tensile tests were $526 \mathrm{MPa}$ and $516 \mathrm{MPa}$ for the $12 \mathrm{~mm}$ and $16 \mathrm{~mm}$ diameter bars respectively.

\subsection{Instrumentation and test set-up}

The reaction forces under the steel plate were measured using 6-8 load cells as indicated in Fig. 9d. These measurements were used to monitor the development of the resultant of the reaction forces. The slab rotations $(\psi)$ were measured along the $x$ and $y$ axes using four inclinometers placed close to the edges of the slabs (Fig. 9e). The slab rotations $\psi_{x}$ and $\psi_{y}$ were also measured in one quadrant of the slab using an inclino-deformeter which is a manual measurement device allowing to measure rotations and elongations on a grid of targets (Fig. 9e) at selected load stages. The values of $\psi_{x} \& \psi_{y}$ corresponding to each triangle of the grid were used to estimate the rotation $\psi$ of the slab for different radial directions along the control perimeter.

\subsection{Test results}

The load arrangement had a significant influence on the type of failure and failure load which was otherwise expected from existing experimental evidence [2,14]. Fig. 10 shows that the slabs failed due to the formation of punching cones except for specimen AM03. In test AM03 the slab bending deformations exceeded the rig capacity and the test was stopped before the punching cone could developed. However, at this stage during test AM03 the flexural mechanism (plastic hinge) had already developed fully (Fig. 10d). The ultimate failure loads in the tests are given in Table 1. The flexural capacity in specimen AM03 was clearly reached whereas in the remaining tests, failure was governed by the development of a punching cone. The ultimate strength of test AM03 was confirmed by a yield-line analysis of the flexural strength considering the actual effective depth of the slab $\left(d_{\text {avg. }}\right.$.) and the development of a single yield line parallel to $c_{\max }$ and running across the entire slab at the edge of the column. The yield line analysis for AM03 resulted in $V_{\text {test }} / V_{\text {flex }}=1.10$ with $V_{\text {flex }}=4 m_{R x} B / \Delta$ where $m_{R x}$ is the plastic moment $(166 \mathrm{kN}), B$ is the width of the slab $(1.5 \mathrm{~m})$ and $\Delta$ is the distance from the load to the edge of the column (1.24 m). A similar yield line mechanism was adopted for AM01-02 with the yield line running parallel to $c_{\min }\left(V_{\text {flex }}=\right.$ $\left.4 m_{R y} B / \Delta\right)$; in this case $\Delta=990 \mathrm{~mm}$ and $m_{R y}=163-157 \mathrm{kN}$ for AM01-02 respectively. Table 3 presents the estimates of $V_{\text {test }} / V_{\text {flex }}$ in all specimens, showing failure loads close to the flexural capacity in tests AM01 and AM02 and loads clearly below the flexural capacity for specimen AM04.

Fig. 11 shows the load-rotation relationships measured in the tests in both $y$ and $x$ directions. Test AM04 had a symmetrical response in terms of slab rotations $\left(\psi_{x}=\psi_{y}\right)$ whereas in specimens AM01, AM02 and AM03 the rotation corresponding to the loading direction was considerably larger than the other, especially in AM03. The slope of the failure cone in tests AM01 and AM02 was generally steeper at the face corresponding to the maximum slab rotations ( $\mathrm{N}-\mathrm{S}$ axis, Fig. 10d). This observation is in agreement with previous findings from tests with square columns and nonsymmetrical rotations [6].

The load cells confirmed that the reaction forces concentrated towards the corners of the column (Fig. 12a-c), especially in tests AM01 and AM02 with one-way spanning along the direction of $c_{\text {max }}$. Load cells " $C$ " (Fig. 9d) measured pressure values, which were significantly lower compared to load cells " $A$ " and "B" placed at the ends of the plates; in AM01 and AM02 the readings from load cells "C" were almost zero (Fig. 12a). LVDT's placed at the top of the slab, 
Table 3

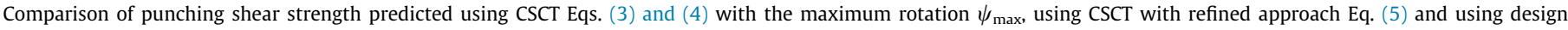
formulas in ACI 318-11 [15], BS8110 [13], EC2 [12] and MC2010 [17].

\begin{tabular}{|c|c|c|c|c|c|c|c|c|c|c|c|}
\hline \multirow[t]{2}{*}{ Test } & \multirow[t]{2}{*}{$V_{\text {test }} / V_{\text {flex }}$} & \multirow[t]{2}{*}{$r_{s x}(\mathrm{~mm})^{\mathrm{a}}$} & \multirow[t]{2}{*}{$V / m_{E x}^{a}$} & \multirow[t]{2}{*}{$r_{s y}(\mathrm{~mm})^{\mathrm{a}}$} & \multirow[t]{2}{*}{$V / m_{E y}{ }^{\mathrm{a}}$} & \multicolumn{2}{|l|}{$V_{\text {test }} / V_{C S C T}{ }^{\mathrm{b}}$} & \multicolumn{4}{|c|}{$V_{\text {test }} / V_{R, c}$} \\
\hline & & & & & & $\psi_{\max }$ in Eq. $(3)$ & $\psi_{x}-\psi_{y}$ Eq. (5) & $\mathrm{EC} 2$ & BS8110 & ACI 318 & MC2010 \\
\hline AM01 & 0.96 & 1118 & 11.0 & 1143 & 5.3 & 1.02 & $0.96^{\mathrm{c}}$ & $0.96^{\mathrm{c}}$ & $0.96^{\mathrm{c}}$ & $0.96^{\mathrm{c}}$ & 1.19 \\
\hline AM02 & 0.96 & 1118 & 11.0 & 1143 & 5.3 & 1.15 & $0.96^{\mathrm{c}}$ & $0.96^{\mathrm{c}}$ & $0.96^{\mathrm{c}}$ & $0.96^{\mathrm{c}}$ & 1.34 \\
\hline AM03 & 1.10 & 1500 & 4.6 & 772 & 12.6 & 1.17 & $1.10^{c}$ & $1.10^{\mathrm{c}}$ & $1.10^{\mathrm{c}}$ & $1.10^{\mathrm{c}}$ & 1.37 \\
\hline AM04 & 0.80 & 1500 & 7.1 & 1191 & 7.6 & 1.12 & 1.09 & 0.96 & 1.03 & 1.04 & 1.31 \\
\hline \multicolumn{12}{|l|}{ Moe [1] } \\
\hline $\mathrm{R} 1$ & 0.91 & 889 & 7.4 & 679 & 7.1 & 1.13 & 1.13 & 1.08 & 1.00 & 1.51 & 1.31 \\
\hline \multicolumn{12}{|c|}{ Hawkins et al. [2] } \\
\hline 2 & 0.94 & 1066 & 7.6 & 880 & 5.3 & 1.00 & 0.99 & 0.98 & 0.94 & 1.07 & 1.13 \\
\hline 3 & 0.85 & 1066 & 7.4 & 856 & 5.6 & 0.95 & 0.95 & 0.91 & 0.85 & 1.18 & 1.10 \\
\hline 4 & 0.82 & 1066 & 7.2 & 834 & 5.7 & 0.99 & 0.99 & 0.91 & 0.85 & 1.35 & 1.15 \\
\hline 5 & 0.73 & 1066 & 7.4 & 852 & 5.6 & 1.04 & 1.01 & 0.95 & 0.89 & 1.31 & 1.21 \\
\hline \multicolumn{12}{|l|}{ Urban [4] } \\
\hline Pm1/1-0.8 & 0.97 & 850 & 6.4 & 850 & 6.4 & 1.12 & 1.12 & 1.14 & 1.03 & 1.31 & 1.30 \\
\hline $\mathrm{P} 1 / 2-0.8$ & 0.98 & 850 & 7.2 & 733 & 7.2 & 1.06 & 1.05 & 1.15 & 1.01 & 1.22 & 1.23 \\
\hline P1/3-0.8 & 0.97 & 850 & 7.1 & 719 & 6.5 & 1.19 & 1.19 & 1.25 & 1.10 & 1.66 & 1.38 \\
\hline P1/4-0.8bis & 0.89 & 850 & 6.7 & 702 & 6.7 & 1.05 & 1.04 & 1.06 & 0.95 & 1.48 & 1.22 \\
\hline Pm1/1-1.5 & 0.71 & 850 & 6.4 & 850 & 6.4 & 1.16 & 1.17 & 1.19 & 1.07 & 1.69 & 1.34 \\
\hline Pd1/1-1.5 & 0.85 & 850 & 7.3 & 850 & 7.3 & 1.06 & 1.07 & 1.14 & 1.02 & 1.25 & 1.23 \\
\hline $\mathrm{P} 1 / 2-1.5$ & 0.88 & 850 & 7.2 & 733 & 7.2 & 1.21 & 1.19 & 1.28 & 1.12 & 1.72 & 1.40 \\
\hline P1/3-1.5 & 0.76 & 850 & 7.1 & 719 & 6.5 & 1.16 & 1.16 & 1.18 & 1.04 & 1.98 & 1.34 \\
\hline $\mathrm{P} 1 / 4-1.5$ & 0.72 & 850 & 7.2 & 707 & 6.6 & 1.18 & 1.17 & 1.17 & 1.02 & 2.19 & 1.36 \\
\hline \multicolumn{12}{|c|}{ Oliveira et al. [14] } \\
\hline L3b & 0.63 & 605 & 5.4 & 495 & 10.4 & 0.98 & 0.96 & 1.13 & 1.04 & 1.34 & 1.14 \\
\hline L3c & 0.63 & 565 & 6.5 & 685 & 6.6 & 0.97 & 0.88 & 1.07 & 0.97 & 1.28 & 1.13 \\
\hline L1b & 0.51 & 590 & 5.2 & 590 & 5.2 & 1.12 & 1.07 & 1.14 & 1.24 & 1.42 & 1.30 \\
\hline L2b & 0.57 & 600 & 5.2 & 517 & 9.2 & 0.99 & 0.94 & 1.17 & 1.07 & 1.27 & 1.15 \\
\hline $\mathrm{L} 4 \mathrm{~b}$ & 0.63 & 610 & 5.8 & 481 & 11.7 & 0.99 & 0.92 & 1.07 & 0.97 & 1.32 & 1.15 \\
\hline L5b & 0.67 & 620 & 6.1 & 485 & 12.9 & 0.96 & 0.89 & 0.95 & 0.87 & 1.16 & 1.12 \\
\hline L1C & 0.55 & 555 & 6.6 & 880 & 6.6 & 1.13 & 1.02 & 1.14 & 1.24 & 1.42 & 1.31 \\
\hline $\mathrm{L} 2 \mathrm{c}$ & 0.58 & 565 & 7.2 & 765 & 5.7 & 1.04 & 0.88 & 1.06 & 0.98 & 1.16 & 1.21 \\
\hline L4c & 0.70 & 570 & 8 & 647 & 6.8 & 1.05 & 0.92 & 1.06 & 0.97 & 1.31 & 1.22 \\
\hline $\mathrm{L} 5 \mathrm{c}$ & 0.77 & 570 & 8.4 & 587 & 7.1 & 1.04 & 0.93 & 1.00 & 0.92 & 1.24 & 1.21 \\
\hline \multicolumn{12}{|c|}{ Teng et al. [22] } \\
\hline OC11 & 0.81 & 1100 & 7.1 & 1100 & 7.1 & 1.24 & 1.24 & 1.31 & 1.20 & 1.78 & 1.34 \\
\hline OC13-1.6 & 0.77 & 950 & 8 & 823 & 8.6 & 1.19 & 1.16 & 1.13 & 1.03 & 1.49 & 1.37 \\
\hline \multicolumn{12}{|c|}{ Al-Yousif and Regan [10] } \\
\hline 1 & 0.71 & 812 & 6.9 & 471 & 5.8 & 0.97 & 0.93 & 0.90 & 0.76 & 1.24 & 1.13 \\
\hline 2 & 0.80 & 479 & 5.4 & 401 & 9.3 & 1.15 & 1.11 & 1.16 & 0.98 & 1.60 & 1.33 \\
\hline 3 & 0.83 & 495 & 4.9 & 418 & 10.1 & 1.15 & 1.06 & 1.08 & 0.91 & 1.52 & 1.33 \\
\hline \multicolumn{12}{|c|}{ Summary of results (excluding AM01, AM02, AM03) } \\
\hline & & & & & Avg. & 1.08 & 1.04 & 1.09 & 1.00 & 1.42 & 1.25 \\
\hline & & & & & $\mathrm{COV}$ & 0.08 & 0.11 & 0.11 & 0.11 & 0.26 & 0.09 \\
\hline & & & & & $5 \%$ fract. & - & - & 0.91 & 0.85 & 1.11 & 1.12 \\
\hline
\end{tabular}

\footnotetext{
a $r_{S}$ and $V_{E d} / m_{E d}$ were estimated for each orthogonal direction $x-y$ from an elastic (uncracked) FEA according to MC2010 [17].

b $V_{C S C T}$ is the average strength calculated using the $b_{0,3 d}$ rule and LoA-III.

c Predicted failure load limited by the flexural capacity of the slab which is estimated using the yield line approach.
}

along the $y$ axis, confirmed that the slab lifted with respect to the support plate at the centre in AM02 which was expected from the FE predictions. The slabs were simply supported so that the reactions could be monitored during the test. Concrete stubs or castin columns in tests can introduce some confinement and clamping effects depending on the detailing which can be difficult to assess in some cases. However, in normal tests set-ups found in the literature (Tables 3 and 4), these effects were found to be negligible.

The test carried out by the authors represent slabs which are simply supported (Fig. 12d). In reality, in column-slab connections in buildings, the slab is restraint to lift (Fig. 12e). This clamping effect in the slab was investigated by the authors by introducing in the FE models two rigid contact surfaces on top and bottom of the shell elements modelling the slab. Fig. 12e shows the contact pressures obtained in this case at the top and bottom of the slab. The clamping forces that developed at the top $(N)$ shown in Fig. 12e are balanced with the reaction forces at the bottom $(V+N)$ and the shear transferred to the slab $(V)$. The distribution of net contact pressures in the slab, considering both top and bottom contact surfaces, was very similar to that obtained in simply supported slabs (Fig. 12d). This resulted in a similar concentration of shear forces in the slab at the shear-critical region for both fixed and simply supported cases. This was the case for the slabs investigated with uniformly distributed loads. In slabs with loads near the column, the clamping effect needs to be considered accordingly. Other effects such as in-plane confinement were not considered in this work.

\section{Analysis of experimental data}

\subsection{Application of the critical shear crack theory to rectangular columns}

The ultimate punching shear strength and deformation capacity of reinforced concrete slabs can be estimated using the Critical 

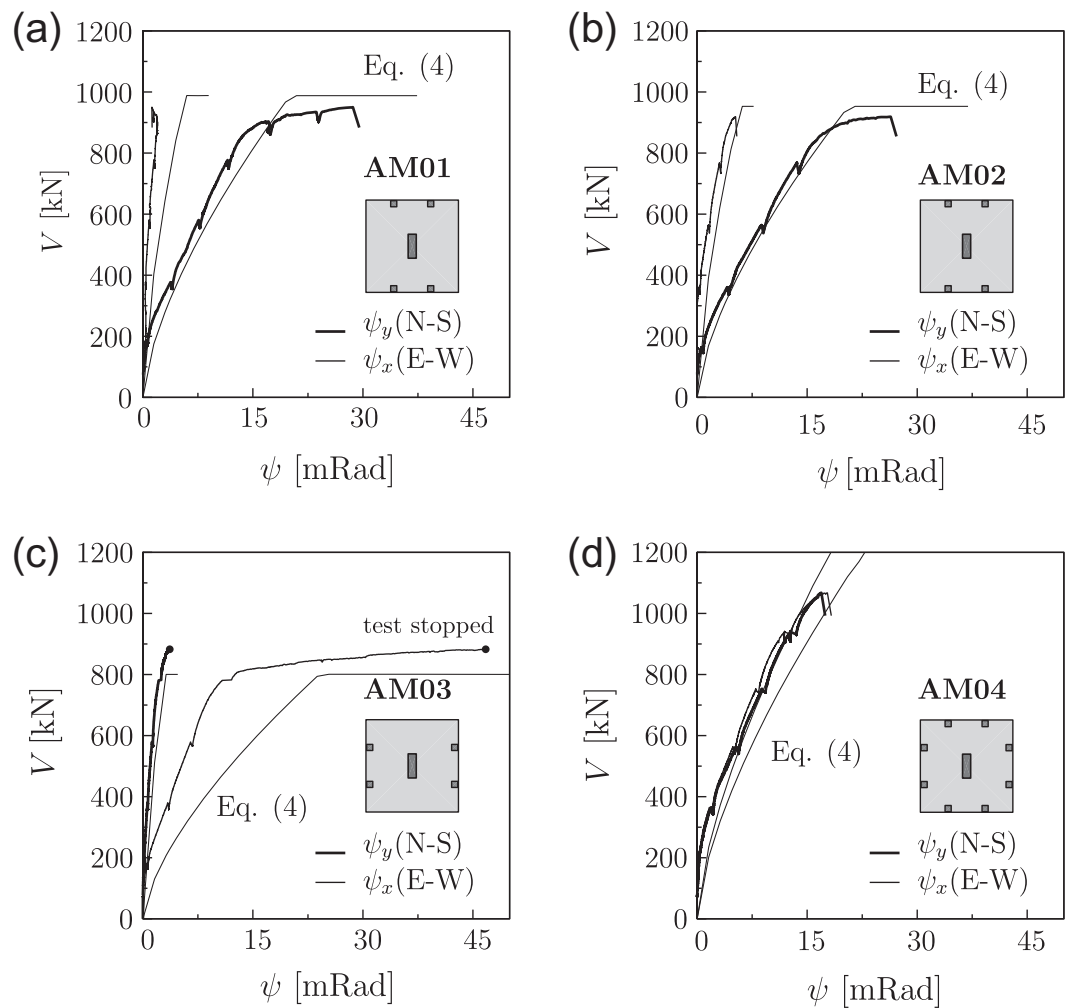

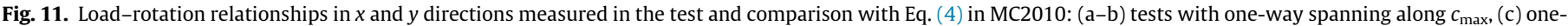
way spanning along $c_{\min }$ and (d) two-way spanning.

Shear Crack Theory (CSCT) as demonstrated by Muttoni [20]. According to this mechanical model the punching shear strength reduces with increasing slab rotations $(\psi)$ due to the increase of the width of the critical shear crack. This relationship is consistent with experimental evidence. For design purposes, a simple expression for the failure criterion was proposed by Muttoni [20]; refer to Eq. (3) for the average punching shear strength.

$\frac{V_{R}}{b_{0} \cdot d \sqrt{f_{c}}}=\frac{3 / 4}{1+15 \frac{\psi \cdot d}{d_{g, 0}+d_{g}}}$

where $d_{g, 0}$ is taken as $16 \mathrm{~mm}$ and $b_{0}$ can be estimated using any of the approaches discussed in this paper $\left(b_{0, e l}, b_{0, p r}\right.$ and $\left.b_{0,3 d}\right)$. Fig. 13 shows that Eq. (3) with the simplified shear-resisting control perimeter $b_{0,3 d}$ captured reasonably well existing experimental data from the literature $[1,2,4,14,22]$. The test data consisted of 33 punching shear tests including slabs tested by the authors; tests cover columns with $c_{\max } / c_{\min }=1-5, c_{\max } / d=1-6$ and one-way $\&$ two-way bending action in which the vertical deflections are known.

In order to determine the punching shear strength and deformation capacity using the CSCT, the intersection between the failure criterion in Eq. (3) and the load-rotation relationship $(V-\psi)$ obtained from a flexural analysis needs to be obtained. The load-rotation relationship of the slab can be estimated using different levels of approximation proposed by the authors which are described in MC2010 [17]. Level of approximation III (LoA-III), given by Eq. (4) was used in this work to estimate the $V-\psi$ relationship in each orthogonal direction.

$\psi=1.2 \frac{r_{s}}{d} \frac{f_{y}}{E_{s}}\left(\frac{m_{E}}{m_{R}}\right)^{3 / 2}$

where $r_{s}$ is the distance from the support to the point where the radial bending moment is zero, $d$ is the effective depth, $f_{y}$ is the yield strength, $E_{S}$ is the Young Modulus of steel reinforcement, $m_{E}$ is the average moment per unit width for calculation of the flexural reinforcement in the support strip for the considered direction [17] and $m_{R}$ is the design average flexural strength per unit width in the support strip for the considered direction.

Parameters $r_{s}$ and $m_{E}$ were estimated in each orthogonal direction using linear elastic (uncracked) finite element models as recommended in MC2010 (LoA-III). The distance $r_{s}$ and the width of the support strip are measured from the support axis which is also assessed in the FEA. The support axis in rectangular columns is near the corners of the column (point $\mathrm{O}$ in Fig. 6c) whereas in square columns with $c / d<3$ this coincides with the centre of the column. LoA-III was suitable in this case since the slabs studied had significant redistribution of bending moments and the geometry irregularity resulted in values of $r_{s}$ and $m_{E}$ slightly different to the standard case of inner columns where $m_{E}=V / 8$ for example. Table 3 shows the values of $r_{s}$ and $m_{E}$ for both orthogonal directions obtained from an elastic FE analysis in the slabs investigated; a summary of the main properties of the tests is given in Table 4 (Appendix B). Fig. 11 shows that the predictions of $V-\psi$ using Eq. (4) were satisfactory in all the slabs tested for both orthogonal directions.

\subsection{Comparison of punching shear strength predicted by design} formulas in ACI 318-11, BS8110, EC2 and MC2010 for two-way and one-way bending

Fig. 14 shows the ratio between the observed punching shear strength $\left(V_{\text {test }}\right)$ and the estimated strength $\left(V_{R, c}\right)$ using the equations in different design codes (ACI 318-11 [15], BS8110 [13], EC2 [12] and MC2010 [17]); refer to Appendix A for formulas. Tests reaching the flexural capacity of the slab were excluded from this analysis, including tests AM01-02-03 tested by the authors. Fig. 14a, b and Table 3 show that EC2 and BS8110 provided relatively similar results. It is noticeable in this case that the ratio $V_{\text {test }} / V_{R, c}$ is consistently decreasing (even below 1 ) for tests with one-way bending along the direction of $c_{\max }$, especially for tests with high values of $c_{\max } / d$ and $c_{\max } / c_{\text {min }}$. The $5 \%$ lower fractile obtained using EC2 and 
(a)

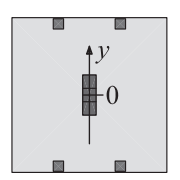

AM02

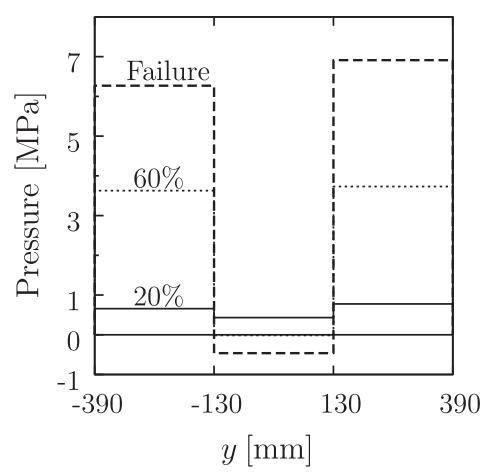

(b)

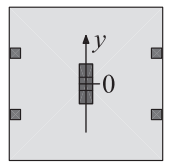

AM03

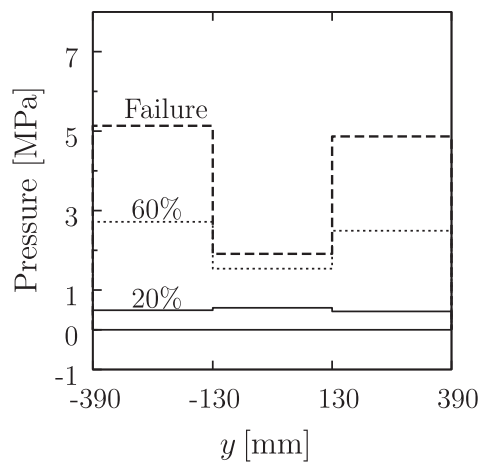

(d)

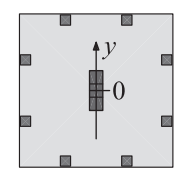

AM04

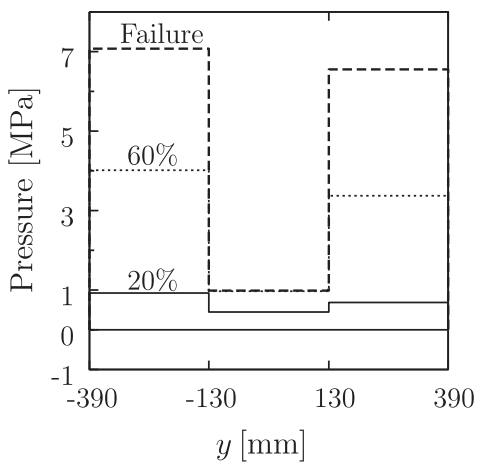

(d)

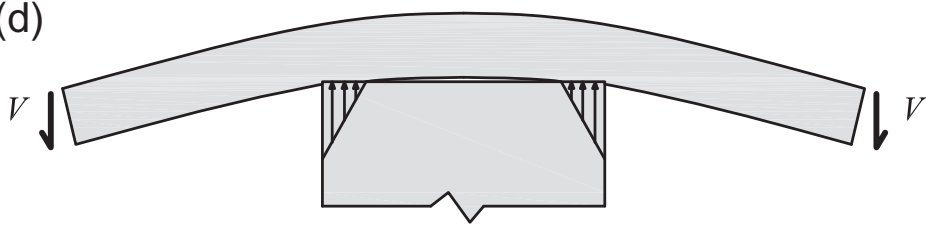

(e)

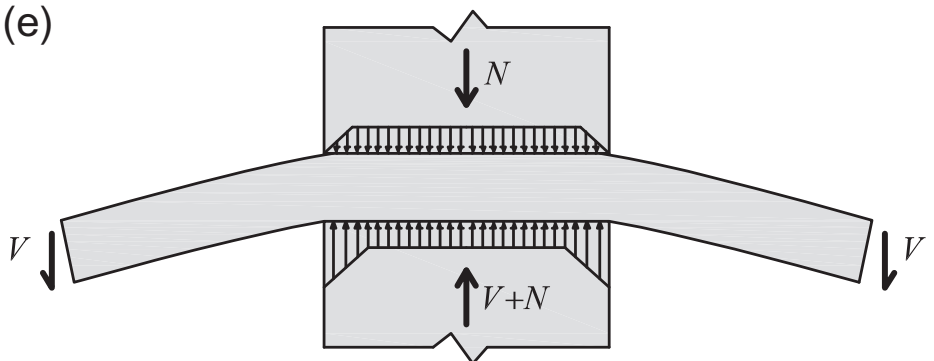

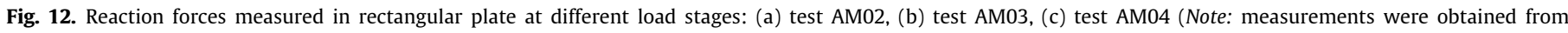

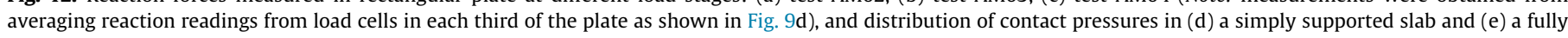
clamped slab at top and bottom (fixed column).

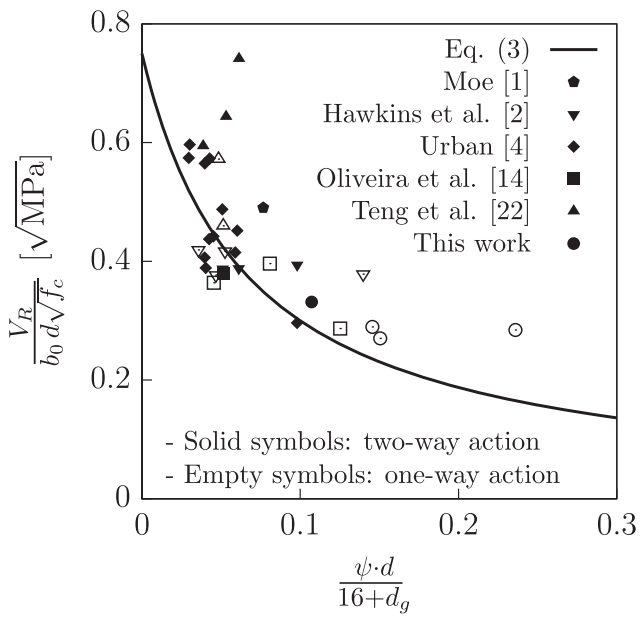

Fig. 13. Punching shear strength of tests with rectangular supports: normalized punching strength vs. normalized maximum rotation using shear-resisting control perimeter $b_{0,3 d}$.
BS8110 was 0.91 and 0.85 respectively (Table 3) which is on the unsafe side. This was also observed by Oliveira et al. [14] using BS8110 equations for which an amendment was proposed.

With respect to EC2, shear field analyses were carried out to determine the value of $b_{0, e l}$ at $2 d$ from the edge of the column. The results indicated that the $b_{0, e l} / b_{1}$ ratio was around 1 in tests with two-way bending whereas $b_{0, e l} / b_{1}$ was around 0.8 and 0.9 for tests with one-way bending along $c_{\max }$ and $c_{\min }$ respectively. Reducing the basic perimeter by $20 \%$ and $10 \%$ in EC2 for cases of one-way bending along $c_{\max }$ and $c_{\min }$ respectively, as suggested by the shear field analyses, resulted in a higher consistency between the strength predictions of one-way and two-way bending. For example, in Fig. 14a, if the perimeter is reduced by $20 \%$, the points below line $V_{R} / V_{R, c}=1$ corresponding to one-way bending $\left(c_{\max }\right)$ moved above this line to around $V_{\text {test }} / V_{R, c}=1.15$ which is more consistent with the rest of experimental data.

Fig. 14c shows that the ACI method provides for the investigated specimens a reasonable lower bound of the test data provided that parameter $\alpha$ is included in the calculation as required in the code, which takes into account column rectangularity and size (refer to Eq. (6) in Appendix A). The scatter in the predictions 

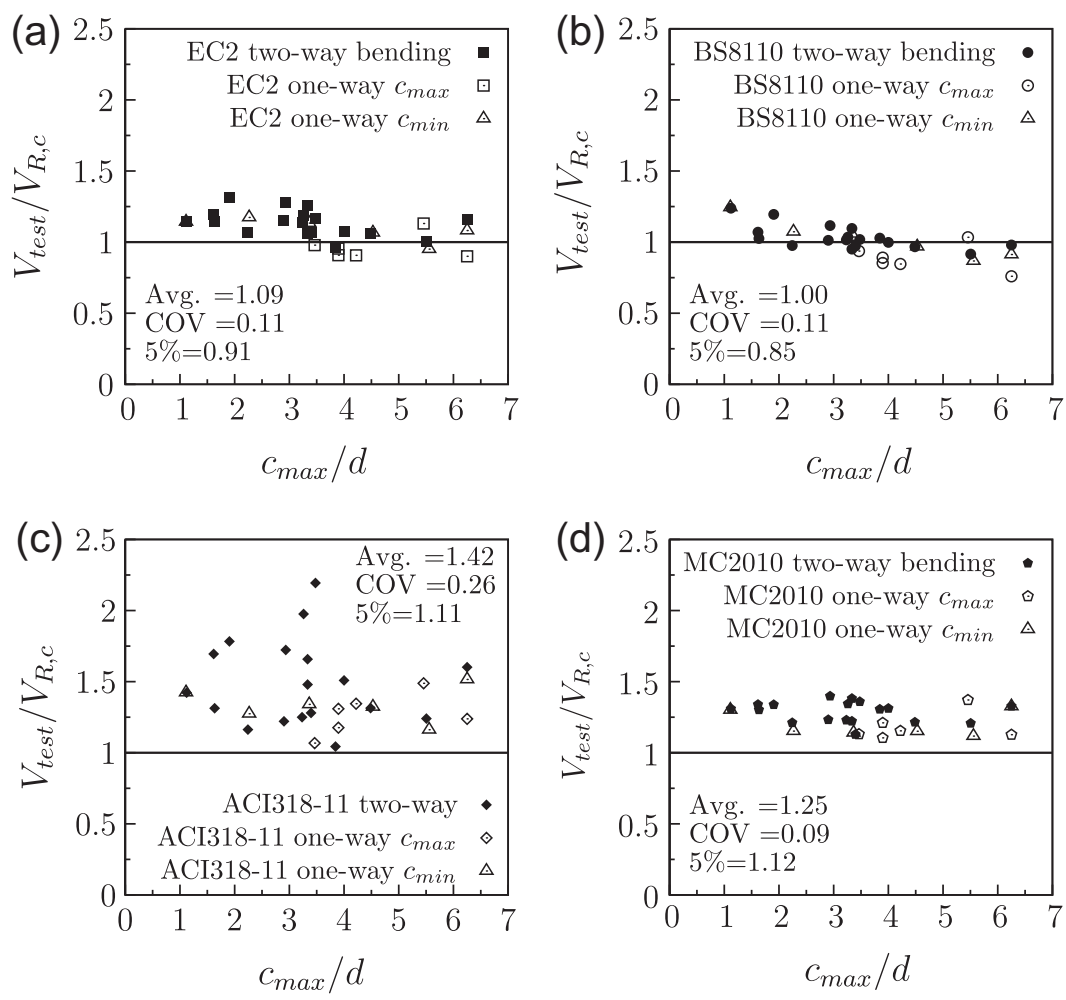

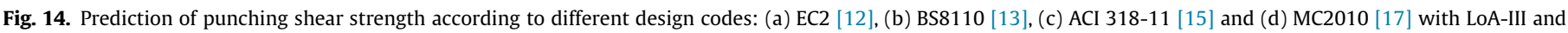
$b_{0,3 d \text {. }}$

(a)

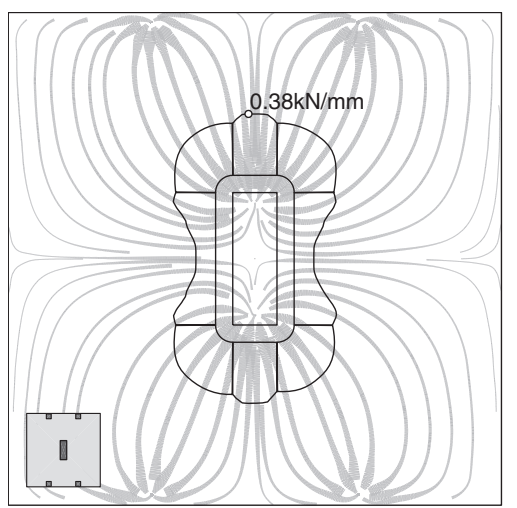

(c)

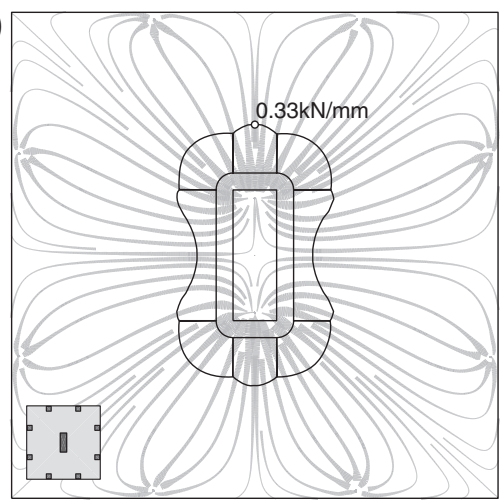

(b)

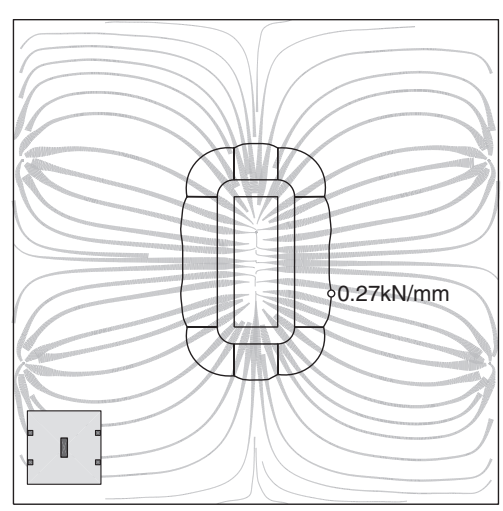


is significant, as expected otherwise since the influence of the reinforcement ratio is not considered. Fig. 14d shows that MC2010 design approach using $b_{0,3 d}$ and LoA-III provided a satisfactory level of safety for both one-way and two-way bending with an average ratio $V_{\text {test }} / V_{R, c}=1.25, \mathrm{COV}=0.09$ and $5 \%$ lower fractile equal to 1.12 .

\subsection{Advanced punching analyses accounting for redistributions on the shear field due to shear crack propagation}

In this section, a general method presented in [6] to account for redistribution on the shear field due to propagation of shear cracks will be extended to the case of elongated columns. Punching shear in slabs with predominant one-way bending deformation is influenced by (i) variation of the nominal shear force and (ii) variation of the nominal punching shear resistance around the control perimeter. It has been shown that the first effect can be considered by means of the shear-resisting control perimeter. Fig. 15 shows the distribution of the nominal shear force obtained in the slabs tested in this work from the shear stress field analysis using an elastic FE analysis. This analysis showed that the maximum nominal shear force along the basic control perimeter $\left(v_{\max }\right)$ corresponded to slabs AM01-02 (one-way bending along $c_{\max }$ ) shown in Fig. 15a, whereas the value of $v_{\max }$ was lowest in slab AM03 (Fig. 15b). Therefore, the estimated shear-resisting control perimeter $\left(b_{0, e l}\right)$ was lowest in AM01-02 and highest in AM03. The distribution of shear in AM03 (Fig. 15b) suggests that $b_{0,3 d}$ can be slightly conservative for AM03 although in this case $b_{0, e l}$ was only $6 \%$ larger than $b_{0,3 d}$ so the difference in terms of predicted strength was not significant. In AM01 and AM02, $b_{0, e l}$ was lower than $b_{0,3 d}$ by $30 \%$ although in this case the actual shear-resisting control perimeter could be underestimated as $b_{0, e l}$ does not consider cracking and redistribution of bending
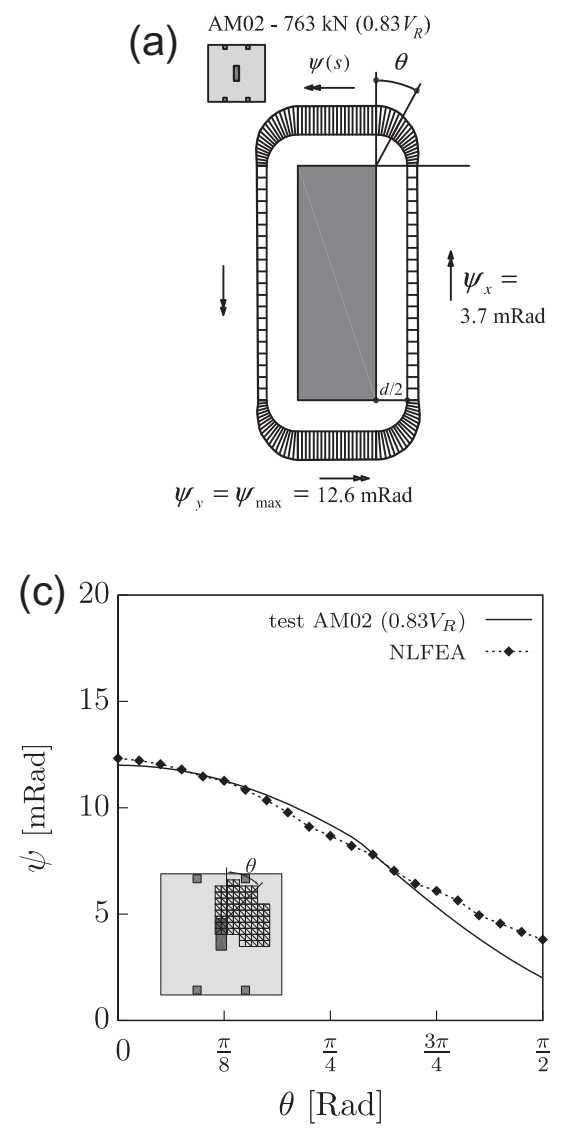

moments. The differences in the predicted value of the shear-resisting control perimeter in the slabs tested by the authors have a relatively small effect on $V_{\text {test }} / V_{\text {CST }}$. The average value of $V_{\text {test }} / V_{\text {CST }}$ using Eq. (3) (column 7th in Table 3) was 1.12 and 1.18 using $b_{0,3 d}$ and $b_{0, e l}$ respectively.

Regarding the nominal punching shear resistance, design codes normally assume a constant nominal strength along the control perimeter. For example in MC2010 the nominal strength $V_{R} / b_{0}$ is assumed constant using Eq. (3) in which $\psi$ is taken as the maximum rotation of the slab. In reality, the nominal strength varies along the control perimeter as the slab rotation varies for each radial direction considered $\psi(s)$; wider cracks due to larger rotations being associated to lower punching strength. Fig. 16a and b shows the estimated slab rotations along different directions considered in the control perimeter in slabs AM02 and AM03; these were estimated from a non-linear finite element analysis (NLFEA). The NLFEA consisted of shell elements considering plastic redistribution of moments due to concrete crushing, cracking and yielding of the reinforcement. The results from the NLFEA were validated against the measurements from inclinometers and inclino-deformeter as shown in Fig. $16 \mathrm{c}$ and $\mathrm{d}$. According to the CSCT, the nominal punching shear strength is related to the slab rotation. For instance, the distribution of the nominal punching shear strength in Fig. 17a for AM02 was obtained from the slab rotations in Fig. 16a. In AM02 the nominal shear strength is lower in the segment of the control perimeter corresponding to $c_{\mathrm{min}}$. The total strength can be calculated by integrating the nominal strength along the entire shear-resisting control perimeter as demonstrated by Sagaseta et al. [6]. This calculation can be simplified by dividing the shear-resisting control perimeter $b_{0}$ into four sectors corresponding to the $x$ and $y$ directions in which the rotation is assumed constant as shown in Fig. 17b.
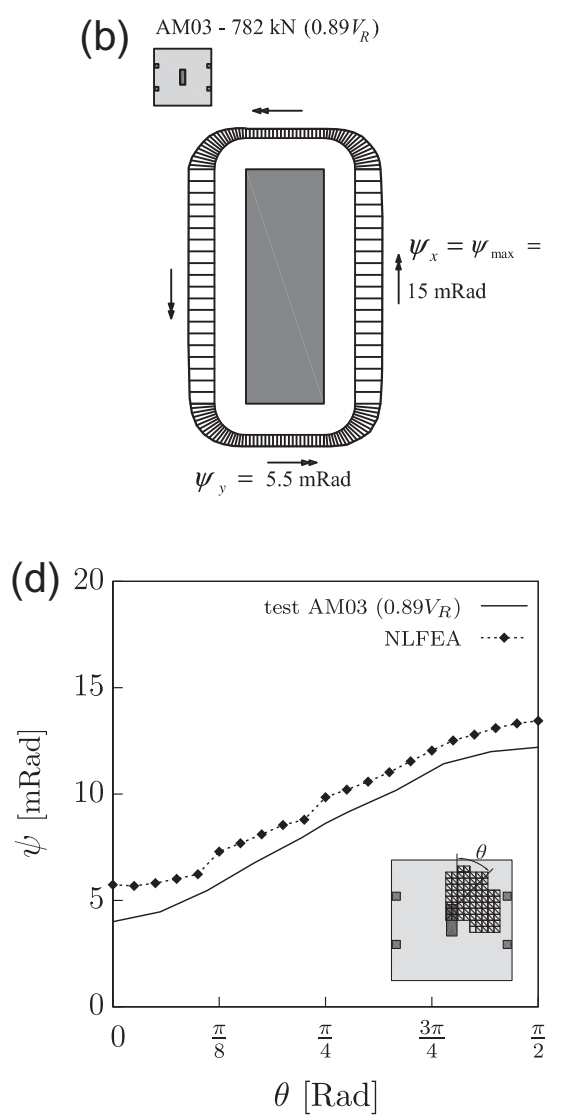

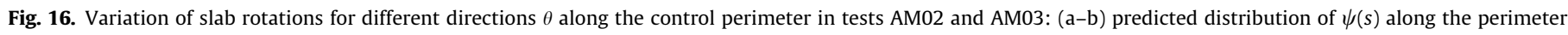
according to a NLFEA and (c-d) measured and predicted slab rotations at corners. 
(a)

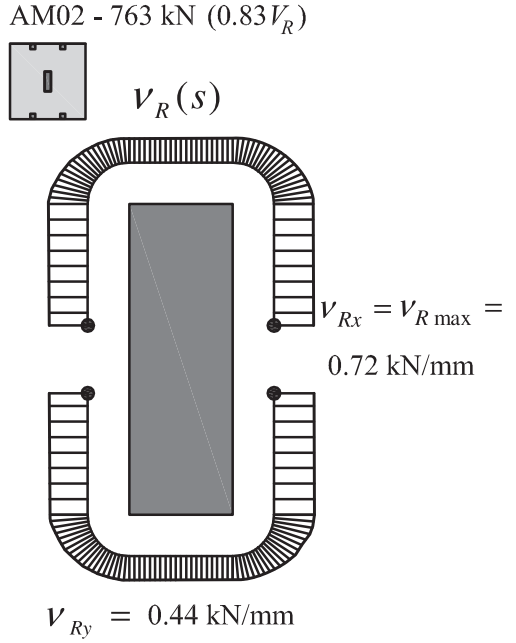

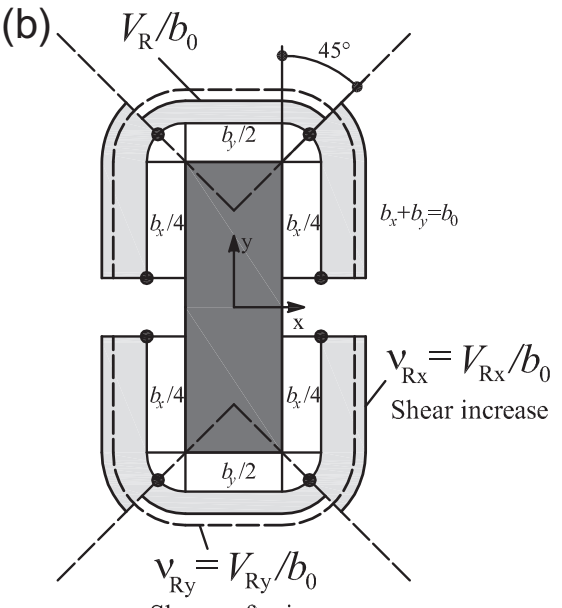

Shear softening

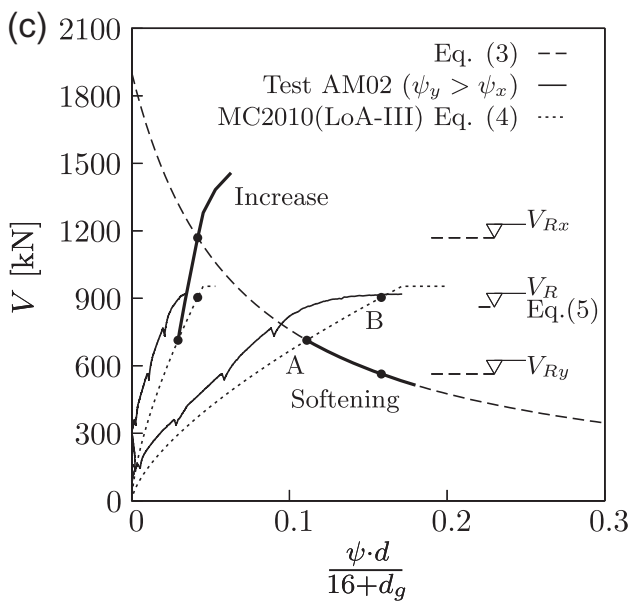

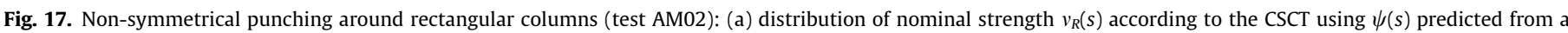

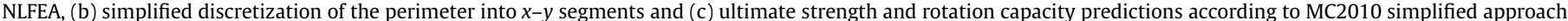
using $\psi_{\max }$ (point A) and the proposed refined method using Eq. (5) with shear redistribution (point B).

In reality, once the maximum rotations in one direction reach the failure criterion (i.e. point A in Fig. 17c) parts of the perimeter will reach their ultimate strength whereas others still have a potential strength capacity. This results in a redistribution of shear forces with a shear softening near the areas with maximum rotations which is balanced with a shear increase in the areas with lower rotations (i.e. higher strength). The redistribution of shear can be taken into account using the CSCT and considering the slab rotations $\psi_{x}$ and $\psi_{y}$ using a similar approach as described by Sagaseta et al. [6] for square columns. The punching shear strength is calculated according to Eq. (5)

$V_{R}=v_{R x} b_{x}+v_{R y} b_{y}=\frac{V_{R x}}{b_{0}} b_{x}+\frac{V_{R y}}{b_{0}} b_{y}$

where $V_{R x}$ and $V_{R y}$ are the strengths calculated using Eq. (3) with $\psi_{x}$ and $\psi_{y}$ respectively and $b_{x}-b_{y}$ are the segments from the shear-resisting control perimeter corresponding to the $x-y$ directions. This approach provides a more refined prediction of strength and deformation capacity than MC2010 approach which considers $\psi_{\max }$ only; although for design purposes the later approach seems more practical. Columns 7th and 8th in Table 3 show that there is a slight reserve in strength due to the shear redistribution which can be estimated using Eq. (5). This is also shown in Fig. 17c in test AM02 where points $\mathrm{A}$ and $\mathrm{B}$ correspond to simplified and refined approaches respectively. The refined approach given by Eq. (5) also provides a physical explanation behind the actual contribution of each segment of the control perimeter towards the overall punching strength.

\section{Conclusions}

This paper presents the results from the analytical and experimental research on punching shear of flat slabs without transverse reinforcement supported by rectangular columns. Two approaches were investigated to assess the shear-resisting control perimeter due to the concentration of shear forces near the corners of the column. The main conclusions are the following:

1. The reduction in punching strength due to the concentration of shear forces near the corners of rectangular columns and square columns with $c / d>3$ depends on the bending deflections of the slab and column geometry. However, in such cases most of design codes consider the column geometry only. This simplification can result in unconservative predictions of the punching strength using EC2 in slabs with one-way action along the long direction of an elongated column.

2. It is shown that this problem can be solved for any general case of loading, boundary conditions and column geometry by using a shear-resisting control perimeter which can be estimated from a shear field analysis or a proposed method based on the contact pressure at the support area. 
3. In general cases of two-way action in a slab, the proposed method and the shear fields provide comparable predictions of the shearresisting control perimeter to the simplified formulas in MC2010. However, these two approaches are more consistent between cases of one-way and two-way action than simplified approaches based on the geometry of the supported area.

4. The simplified formulas proposed in the new MC2010 for estimating the shear-resisting control perimeter $\left(b_{0,3 \mathrm{~d}}\right)$ and the load-rotation relationship can be safely applied to rectangular columns to estimate the punching strength and deformation capacity. The design approach achieved a ratio for the $5 \%$ lower fractile equal to 1.12 .

5. The tests in this work showed that the failure mode, ultimate strength and rotation capacity were highly influenced by the orientation of the column with respect to the main spanning direction. As expected, the reaction forces under the bearing plate moved towards the edges of the column, especially in the tests with one-way action along the long direction of an elongated column.

6. Tests with rotations which are significantly larger in one direction showed a residual capacity compared to slabs with equal rotations in both directions. This is due to a redistribution of shear which can be quantified using the theoretical model previously developed by the authors for non-axis-symmetrical punching in square columns. Although this refined approach gives more accurate predictions of strength and deformation capacity in such cases, the MC2010 simplified method using the maximum rotations seems more suitable for design purposes.

\section{Acknowledgements}

The authors would like to thank Professor Neil Hawkins for the additional information provided on slab deformations in tests [2] used in Fig. 13; and Dr. Renata Kotynia and Dr. Susanto Teng for providing additional information of tests regarding the maximum aggregate size $\left(d_{g}=16 \mathrm{~mm}\right.$ for tests [4] and $d_{g}=20 \mathrm{~mm}$ for tests [22]). The authors would also like to express their gratitude to Dr. Stefan Lips for his contribution in the experimental work.

\section{Appendix A. Punching shear formulas in design codes $[15,13,12,17]$}

- The punching shear strength according to ACI 318-11 is

$$
V_{R}=\frac{1}{3} \alpha \sqrt{f_{c}} b_{1} d
$$

where $\alpha$ is the lowest of $\left(0.5+c_{\min } / c_{\max }\right),\left(0.5+10 d / b_{1}\right)$ for internal columns and $1 ; b_{1}$ is the length of the basic perimeter.

- The punching shear strength according to BS8110 is

$$
V_{R}=0.27 b_{0} d(400 / d)^{1 / 4}\left(100 \rho_{l} f_{c u}\right)^{1 / 3}
$$

where $\rho_{l}=\left(\rho_{x}+\rho_{y}\right) / 2$.

Table 4

\begin{tabular}{|c|c|c|c|c|c|c|c|c|c|c|c|}
\hline Test & Load $^{\mathrm{a}}$ & $d(\mathrm{~mm})$ & $C_{\max (\mathrm{mm})}$ & $c \max / d$ & $\mathrm{cmax} / \mathrm{cmin}$ & $f c(\mathrm{MPa})$ & $d g(\mathrm{~mm})$ & $\rho_{x}(\%)$ & $\rho_{y}(\%)$ & $f y(\mathrm{MPa})$ & Vtest $(\mathrm{kN})$ \\
\hline \multicolumn{12}{|l|}{ Moe [1] } \\
\hline R1 & $2 w$ & 114 & 457 & 4.00 & 3.00 & 27.1 & 10 & 1.29 & 1.48 & 327 & 393 \\
\hline \multicolumn{12}{|c|}{ Hawkins et al. [2] } \\
\hline 2 & 1wa & 117 & 406 & 3.46 & 2.00 & 28.1 & 19 & 1.2 & 1.04 & 411 & 351 \\
\hline 3 & 1wa & 117 & 457 & 3.90 & 3.00 & 29.9 & 19 & 1.2 & 1.04 & 411 & 333 \\
\hline 4 & $1 \mathrm{wa}$ & 117 & 495 & 4.22 & 4.33 & 29.3 & 19 & 1.2 & 1.04 & 411 & 330 \\
\hline 5 & 1wa & 117 & 457 & 3.90 & 3.00 & 27.4 & 19 & 1.2 & 1.04 & 411 & 355 \\
\hline \multicolumn{12}{|l|}{ Urban [4] } \\
\hline $\operatorname{Pm} 1 / 1-0.8$ & $2 w$ & 98 & 160 & 1.63 & 1.00 & 26.7 & 16 & 0.73 & 0.89 & 413 & 210 \\
\hline $\mathrm{P} 1 / 2-0.8$ & $2 w$ & 92 & 267 & 2.90 & 2.01 & 27.9 & 16 & 0.77 & 0.95 & 417 & 215 \\
\hline $\mathrm{P} 1 / 3-0.8$ & $2 w$ & 90 & 300 & 3.33 & 3.00 & 21.9 & 16 & 0.79 & 0.97 & 418 & 210 \\
\hline $\mathrm{P} 1 / 4-0.8$ bis & $2 w$ & 99 & 330 & 3.33 & 4.13 & 30.1 & 16 & 0.72 & 0.88 & 420 & 225 \\
\hline Pm1/1-1.5 & $2 w$ & 99 & 160 & 1.62 & 1.00 & 23.9 & 16 & 1.27 & 1.62 & 415 & 260 \\
\hline Pd1/1-1.5 & $2 w$ & 99 & 320 & 3.23 & 1.00 & 30.1 & 16 & 1.27 & 1.62 & 416 & 360 \\
\hline $\mathrm{P} 1 / 2-1.5$ & $2 w$ & 91 & 267 & 2.93 & 2.01 & 19.8 & 16 & 1.21 & 1.83 & 352 & 252 \\
\hline $\mathrm{P} 1 / 3-1.5$ & $2 w$ & 92 & 300 & 3.26 & 3.00 & 16.0 & 16 & 1.20 & 1.81 & 353 & 220 \\
\hline $\mathrm{P} 1 / 4-1.5$ & $2 w$ & 92 & 320 & 3.48 & 4.00 & 14.6 & 16 & 1.20 & 1.81 & 354 & 210 \\
\hline \multicolumn{12}{|c|}{ Oliveira et al. [14] } \\
\hline L3b & $1 \mathrm{wb}$ & 107 & 360 & 3.36 & 3.00 & 60.0 & 16 & 1.06 & 1.03 & 749 & 400 \\
\hline $\mathrm{L} 3 \mathrm{C}$ & $2 w$ & 106 & 360 & 3.40 & 3.00 & 54.0 & 16 & 1.06 & 1.03 & 749 & 358 \\
\hline L1b & $1 \mathrm{wb}$ & 108 & 120 & 1.11 & 1.00 & 59.0 & 16 & 1.06 & 1.03 & 749 & 322 \\
\hline L2b & $1 w b$ & 106 & 240 & 2.26 & 2.00 & 58.0 & 16 & 1.06 & 1.03 & 749 & 361 \\
\hline L4b & $1 \mathrm{wb}$ & 106 & 480 & 4.53 & 4.00 & 54.0 & 16 & 1.06 & 1.03 & 749 & 395 \\
\hline L5b & $1 w b$ & 108 & 600 & 5.56 & 5.00 & 67.0 & 16 & 1.06 & 1.03 & 749 & 426 \\
\hline L1C & $2 w$ & 107 & 120 & 1.12 & 1.00 & 59.0 & 16 & 1.06 & 1.03 & 749 & 318 \\
\hline L2c & $2 w$ & 107 & 240 & 2.24 & 2.00 & 57.0 & 16 & 1.06 & 1.03 & 749 & 331 \\
\hline L4c & $2 w$ & 107 & 480 & 4.49 & 4.00 & 56.0 & 16 & 1.06 & 1.03 & 749 & 404 \\
\hline L5c & $2 w$ & 109 & 600 & 5.50 & 5.00 & 63.0 & 16 & 1.06 & 1.03 & 749 & 446 \\
\hline \multicolumn{12}{|c|}{ Teng et al. [22] } \\
\hline OC11 & $2 w$ & 105 & 200 & 1.90 & 1.00 & 36.0 & 20 & 1.81 & 1.81 & 453 & 423 \\
\hline OC13-1.6 & $1 w a^{b}$ & 110 & 600 & 5.45 & 3.00 & 32.9 & 20 & 1.71 & 1.71 & 470 & 508 \\
\hline \multicolumn{12}{|c|}{ Al-Yousif and Regan [10] } \\
\hline 1 & 1 wa & 80 & 500 & 6.25 & 5.00 & 23.6 & 10 & 1.04 & 0.92 & 472 & 163 \\
\hline 2 & $2 w$ & 80 & 500 & 6.25 & 5.00 & 23.2 & 10 & 1.04 & 0.92 & 473 & 209 \\
\hline 3 & $1 \mathrm{wb}$ & 80 & 500 & 6.25 & 5.00 & 21.2 & 10 & 0.92 & 1.04 & 474 & 189 \\
\hline
\end{tabular}

Experimental database from the literature $[1,2,4,14,22,10]$.

a Type of loading: $2 \mathrm{w}=$ two-way action; $1 \mathrm{wa}=$ one-way action along $c_{\max } ; 1 \mathrm{wb}=$ one-way action perpendicular to $c_{\text {max }}$.

b Test with loads in both directions (load $60 \%$ higher in the direction of $c_{\max }$ ). Shear field analysis of this test showed that the behaviour of the slab was closer to 1 wa than $2 \mathrm{w}$. 
- The punching shear strength according to EC2 is

$$
V_{R}=0.18 b_{0} d(1+\sqrt{200 / d})\left(100 \rho_{l} f_{c}\right)^{1 / 3}
$$

where $(1+\sqrt{200 / d}) \leqslant 2.0$ and $\rho_{l}=\sqrt{\rho_{x} \rho_{y}}$.

- The punching shear strength according to MC2010 is

$$
V_{R}=k_{\psi} \sqrt{f_{c}} b_{0} d
$$

where $k_{\psi}=\frac{1}{1.5+0.9 k_{d g} \psi d} \leqslant 0.6$ and $k_{d g}=\frac{32}{16+d_{g}} \geqslant 0.75$.

The rotation around the supported area $\psi$ was calculated in this work according to LoA-III given by Eq. (4). For large or elongated columns, the shear-resisting control perimeter can be estimated as $b_{0,3 \mathrm{~d}}$ or $b_{0, \mathrm{el}}$.

All safety factors were taken as 1.0 for comparison with tests results. Eqs. 6-9 use SI units $(\mathrm{N}, \mathrm{mm})$. The control perimeters are located at $0.5 d, 1.5 d, 2 d$ and $0.5 d$ from the column face in $\mathrm{ACI}$ 318-11, BS8110, EC2 and MC2010 respectively. The control perimeters adopted had round corners in all cases except for BS8110 which uses straight sides; ACI 318-11 also allows using straight sides although this option was not adopted in this work for consistency with the other approaches. Column rectangularity is only considered in approaches in ACI 318-11 and MC2010.

\section{Appendix B. Summary of experimental data}

See Table 4.

\section{References}

[1] Moe J. Shearing strength of reinforced concrete slabs and footing under concentrated loads. Development department bulletin D47. Portland Cement Association; 1961. p. 135p.

[2] Hawkins NM, Falssen HB, Hinojosa RC. Influence of column rectangularity on the behaviour of flat plate structures. ACI Spec Publ 1971;SP-30:127-46.

[3] Vanderbilt MD. Shear strength of continuous plates. J Struct Div Proc ASCE 1972;:ST5:961-73.

[4] Urban T. (In Polish: Nosnosc na przebicie w aspekcie proporcji bokow slupa), Badania Doswiadczalne Elementów I Konstrukcji Betonowych 1994; Report 3. Lodz, Poland; 1994. 76p.
[5] Vaz Rodrigues R, Fernández Ruiz M, Muttoni M. Shear strength of R/C bridge cantilever slabs. Eng Struct 2008;30:3024-33.

[6] Sagaseta J, Muttoni A, Fernández Ruiz M, Tassinari L. Non-axis-symmetrical punching shear around of RC slabs without transverse reinforcement. Mag Concr Res 2011;63(6):441-57.

[7] CEB - FIP. Model code for concrete structures. CEB 1978. Paris; 1978

[8] Commission of the European Communities. Eurocode no. 2: common unified rules for concrete structures. Directorate-general for internal market and industrial affairs. EUR 8848. Brussels; 1984.

[9] European Prestandard Eurocode 2. Design of concrete structures, Part 1-1. General rules and rules for buildings. prEN 1992-1-1; 1991.

[10] Al-Yousif AT, Regan PE. Punching resistances of RC slabs supported by large and/or elongated columns. Struct Eng 2003;81(5):30-4.

[11] CEB - FIP. Model code 1990: design of concrete structures. CEB-FIP; 1993

[12] CEN European committee for standardization. Eurocode 2. Design of concrete structures - Part 1: general rules and rules for buildings. Brussels, Belgium: CEN. EN 1992-1-1; 2004

[13] British Standards Institution. BS 8110 Part 1: structural use of concrete: code of practice for design and construction. London: BSI; 1997.

[14] Oliveira DR, Regan PE, Melo GS. Punching resistance of RC slabs with rectangular columns. Mag Concr Res 2004;40(3):123-38.

[15] ACI committee 318. Building code requirements for structural concrete (AC 318-11) and commentary. Farmington Hills, MI: ACI American Concrete Institute; 2011.

[16] Swiss society of engineers and architects SIA. Code 262 for concrete structures. Swiss Society of Engineers and Architects, Zürich: SIA; 2013.

[17] fib Fédération international du béton. fib Model Code for Concrete Structures 2010. Ernst \& Sohn: Berlin; 2013. 434p.

[18] Criswell ME. Static and dynamic response of reinforced concrete slab-column connections. ACI Spec Publ 1974;SP-42:721-46.

[19] ACI-ASCE committee 426 on shear and diagonal tension. The shear strength of reinforced concrete members - slabs. J Struct Div Proc ASCE 1974;100(ST8):1543-91.

[20] Muttoni A. Punching shear strength of reinforced concrete slabs without transverse reinforcement. ACI Struct J 2008;105(4):440-50.

[21] Fernández Ruiz M, Muttoni A. Application of shear stress fields for the analysis and design of reinforced concrete slabs (in Spanish). Hormigón Acero 2009;60(252):73-88

[22] Teng S, Cheong HK, Kuang KL, Geng JZ. Punching shear strength of slabs with openings and supported on rectangular columns. ACI Struct J 2004:101(5):678-87.

[23] Anis NN. Shear strength of reinforced concrete slabs without shear reinforcement. PhD thesis. London: Department of Civil Engineering Imperial College London; 1970.

[24] Zaghlool ERF, Paiva HAR. Tests of flat-plate corner column-slab connections. J Struct Div Proc ASCE 1973;99(ST3):551-72.

[25] Simmonds SH. Flat slabs supported on columns elongated in plan. ACI J 1970;67-67:967-76.

[26] Guandalini S, Burdet O, Muttoni A. Punching tests of slabs with low reinforcement ratios. ACI Struct J 2009;106(1):87-95. 